

\title{
Ductile to brittle transition of an A508 steel characterized by Charpy impact test, part I., experimental results
}

Benoit Tanguy, Jacques Besson, Roland Piques, André Pineau

\section{To cite this version:}

Benoit Tanguy, Jacques Besson, Roland Piques, André Pineau. Ductile to brittle transition of an A508 steel characterized by Charpy impact test, part I., experimental results. Engineering Fracture Mechanics, 2005, 72, pp.49-72. 10.1016/j.engfracmech.2004.03.010 . hal-00142084

\section{HAL Id: hal-00142084 \\ https://hal.science/hal-00142084}

Submitted on 23 Apr 2007

HAL is a multi-disciplinary open access archive for the deposit and dissemination of scientific research documents, whether they are published or not. The documents may come from teaching and research institutions in France or abroad, or from public or private research centers.
L'archive ouverte pluridisciplinaire HAL, est destinée au dépôt et à la diffusion de documents scientifiques de niveau recherche, publiés ou non, émanant des établissements d'enseignement et de recherche français ou étrangers, des laboratoires publics ou privés. 


\title{
Ductile to brittle transition of an A508 steel characterized by Charpy impact test. Part-I: experimental results
}

\author{
B. Tanguy ${ }^{\star}$, J. Besson, R. Piques, A. Pineau \\ Ecole des Mines de Paris, Centre des Matériaux, UMR CNRS 7633 \\ BP 87, 91003 Evry Cedex, France \\ * Corresponding author, Phone: (+33) 1.60.76.30.61, Fax: (+33) 1. 60.76.31.50. \\ e-mail address: Benoit.Tanguy@ensmp.fr
}

\begin{abstract}
This study is devoted to the ductile-brittle transition behavior of a French A508 $\mathrm{Cl} 3$ (16MND5) steel. Due to its importance for the safety assessment of PWR vessels, a full characterization of this steel with Charpy V-notch test in this range of temperature was undertaken. The aim of this study is to provide a wide experimental database and microstructural observations to supply, calibrate and validate models used in a local approach methodology. Mechanical and fracture properties of the steel have been investigated over a wide range of temperatures and strain rates. Effects of impact velocity on ductile-brittle transition curve, on ductile tearing and on notch temperature rise are presented and discussed. A detailed study of ductile crack initiation and growth in Charpy specimens is also carried out. From fractographic investigations of the microvoids nucleation around carbide second phase particles, a plastic strain threshold for nucleation is determined for this material. A508 $\mathrm{Cl} 3$ steels undergo a transition in fracture toughness properties with temperature, due to a change in fracture mode from microvoids colaescence to cleavage fracture. A systematic investigation on the nature and the position of cleavage triggering sites and on any change in the ductile to brittle transition (DBT) range has been carried out. This leads to the conclusion that Manganese sulfide inclusions do not play an increasing role with increasing test temperature as recently mentionned in other studies on $\mathrm{A} 508 \mathrm{Cl} 3$ steel with a higher sulfur content. In a companion paper [1], the numerical simulation of the Charpy test in the ductile-brittle transition range using fully coupled local approach to fracture is presented.
\end{abstract}

Key words: Ductile to brittle transition, Charpy test, Local approach, Ductile damage, Cleavage triggering sites 


\section{Introduction}

In spite of its importance in structural integrity assessment, the evaluation of embrittlement of Pressurized Water Reactors (PWR) has been based, for historical reasons, on qualitative notch-impact tests for several decades. However toughness values are required to assess the structural integrity. The determination of the behavior of ferritic structural and pressure vessel steels through the transition temperature range is an important issue in consideration of safety cases for the safe operation.

For a more precise assessment, a better understanding of the Charpy test and of micromechanisms involved in fracture is needed. This is the first step to establish a non-empirical micromechanically based relationship between the Charpy impact energy $(\mathrm{CVN})$ and the fracture toughness in the ductile-brittle transition. This research field has already been the topic of a number of studies. Among these studies many were devoted to nuclear pressure steels such as the A533B steel in the US [2-5], the 22NiMoCr3-7 steel in Germany [6-9] and the A508 Cl3 (16MND5) steel in France [10-16].

Although these materials are very similar, different mechanisms have been proposed as controlling the ductile-brittle transition behavior depending on the applied heat-treatments and chemical composition. Regarding cleavage, different triggering sites have been identified: iron based carbides or carbides colonies [17-19], small round manganese sulfides (MnS) inclusions [18, 20], grain boundaries [21],TiC particles [17, 18]. Even in the case of the French A508 steel for which the heat treament is the same, recent studies have proposed different controlling mechanisms. For instance, $\mathrm{MnS}$ clusters have been identified to be at the origin of cleavage fracture in a steel containing a sulfur content of $0.008 \%$ (wt) $[11,22,23]$. However the role of these MnS clusters as stress concentrators has been questionned in a recent study devoted to the same material [24].

Recent metallurgical improvements have led to significant decrease in sulfur content which can be as low as 0.002-0.004 wt \%. Several western PWR vessels in duty are made of steel with such a low sulfur content $[9,25]$. A better understanding of the ductile to brittle transition (DBT) is still needed.

In parallel with these studies devoted to the improvement of materials for pressure vessels there is now a growing research interest to develop appropriate models based on the study of the micromechanisms of fracture and more often on finite element simulations. This is the so-called methodology of the local approach to fracture. These models apply to either ductile tearing or cleavage fracture [26-28]. Each model has shown good capacity of prediction as long as only one mechanism is involved. However, few studies [4, 6, 7, 12, 15, 16, 22, 23, 29] have been devoted to the complete description of DBT range including the sharp upturn, i.e. when cleavage is preceeded by significant ductile crack growth. To fit and validate the models, a well established experimental database is needed. 
This paper deals with the DBT behavior of a low sulfur A508 Cl3 steel representative of currently operating French PWR. It is devoted to a better understanding of:

(i) the mechanical behavior of this steel over wide temperature and strain rate ranges,

(ii) the microscopic failure processes involved in the DBT range,

(iii) the Charpy test itself.

These test data and microstructural observations are used in a companion paper [1] to develop and validate a model able to represent the whole Charpy transition curve from very low temperature to the upper shelf energy.

This paper first presents the material microstructure and its viscoplastic behavior. Rupture is then studied using notched round bars. An extensive study of the Charpy test is then presented where (i) the effect of impact velocity, (ii) the initiation and propagation of ductile damage, (iii) the nature and position of cleavage triggering sites are described.

\section{Material}

The material used in this study is an A508 Cl3 (16MND5) steel used for the fabrication of PWR vessels and manufactured by Framatome. Table 1 gives its chemical composition. It was heat treated (two austenitizing treatments followed by water quenching and tempering, and a final stress relief treatment) to obtain a tempered bainitic microstructure with a room temperature yield strength $\sigma_{Y}=490 \mathrm{MPa}$ and an ultimate tensile strength, $\sigma_{U T S}=620 \mathrm{MPa}$. The typical microstructure is shown in Fig. 1. The prior austenite grain size is between 20 and $30 \mu \mathrm{m}$ and the mean diameter of bainitic packets is about $8 \mu \mathrm{m}$ [12]. In the following, the metallurgical directions will be referred to as: $\mathrm{L}, \mathrm{T}$ and $\mathrm{S}$ for the longitudinal (tangential direction in a shell), transverse (axial direction in a shell) and short transverse (radial) directions, respectively.

In such steels, inclusions play an important role as they are potential initiation fracture sites for both ductile and brittle fracture. The nature of these inclusions was investigated in previous studies [26, 30]. They mainly consist in Manganese sulfide (MnS), titanium carbides (TiC) and iron carbides $\left(\mathrm{Fe}_{3} \mathrm{C}\right) . \mathrm{MnS}$ and $\mathrm{Fe}_{3} \mathrm{C}$ particles play a key role for both brittle and ductile fracture wheras $\mathrm{TiC}$ are mostly involved in brittle failure but plays a minor role in A508 steels. The relative importance on the fracture mechanisms of $\mathrm{MnS}$ and $\mathrm{Fe}_{3} \mathrm{C}$ particles varies from one heat to another one. In the case of $\mathrm{MnS}$ inclusions, their shape and the volume fraction are well known to be the most important factors controlling ductile fracture. For brittle fracture, less information is available in the litterature. In the case of $\mathrm{Fe}_{3} \mathrm{C}$ precipitates, heat treatment controls their embrittlening effect and therefore affects both ductile and brittle fracture $[31,32]$. 
The present steel has a low sulfur content (0.004 weight \%) which is representative of recent PWR vessels. In particular the sulfur content is lower than in similar steels investigated in previous studies $[11,16,22,23]$ for which the content is equal to 0.008 weight $\%$. An obvious consequence is the increase of the MnS volume fraction. In addition this larger amount in sulfur content also presumably leads to $\mathrm{MnS}$ clustering as shown in $[22,23]$. In this study the MnS volume fraction was evaluated to $1.7510^{-4}$ using both the Franklin formula [33] and image analysis, a good agreement being found between both methods [12]. The mean distance between inclusions in a plane normal to crack front was evaluated to be around $160 \mu \mathrm{m}[12]$.

\section{Viscoplastic behavior of the material in the transition range}

\subsection{Experiments}

Two types of specimens were manufactured : round tensile (RT) specimens $(6.18$ $\mathrm{mm}$ diameter and $44.5 \mathrm{~mm}$ gauge length) with their gauge length parallel to the long transverse (T) orientation; cylindrical compressive specimens (diameter $7 \mathrm{~mm}$ and height $8 \mathrm{~mm}$ ). Tensile specimens were loaded with an Instron servohydraulic machine at a ram displacement rate of $1.07 \mathrm{~mm} / \mathrm{min}$ (mean strain rate of $4.10^{-4} \mathrm{~s}^{-1}$ ), and at temperatures between $-196^{\circ} \mathrm{C}$ and $300^{\circ} \mathrm{C}$. Compressive specimens were loaded using a split Hopkinson bars. Care was taken to obtain a nearly constant strain rate during the test. Strain rates over the range $\left[1.10^{3} \mathrm{~s}^{-1}-4.10^{3} \mathrm{~s}^{-1}\right]$ were explored in the temperature range $\left[-100^{\circ} \mathrm{C}, 300^{\circ} \mathrm{C}\right]$ by this way. A comparison between quasi-static tensile and compressive tests was also made at ambient temperature to check the absence of any significant strength differential effect. The absence of this effect was also assumed under dynamic conditions.

\subsection{Results}

Full analysis of the viscoplastic behavior of the material was reported elsewhere [34]. Here the temperature dependence of the yield stress at different strain rates (see fig. 2) is only reported. It is underlined that, as reported in [34], the strain rate sensitivity of the yield stress exhibits two regimes. More details are given in the companion paper [1]. These two regimes were also evidenced in a mild steel. The physical background of these regimes is explained in [35]. As both temperature effect and strain rates sensitivity have to be considered to obtain an accurate simulation of the Charpy test, constitutive equations were developed to represent the observed yield stress dependences [34] and are given in the companion paper [1]. 


\section{Notched fracture behavior}

\subsection{Experiments}

Axisymmetric notched tensile (NT) specimens were tested. These specimens are defined by the ratio $\rho / \Phi_{0}$ where $\rho$ is the radius of the notch and $\Phi_{0}$ the minimum diameter. In order to obtain different stress states (quantified by the stress triaxiality ratio) in NT specimens, several notch geometries were used. The minimum diameter, $\Phi_{0}$, is equal to $6 \mathrm{~mm}$; the maximum diameter is $10.8 \mathrm{~mm}$ and the notch radius $\rho$ is such that $2 \rho / \Phi_{0}=0.4,0.8$ and 2 corresponding approximately to a mean stress triaxiality ratio of $1.4,1.1$ and 0.8 , respectively [36].

NT specimens were tested over the temperature range $\left[-196^{\circ} \mathrm{C}, 20^{\circ} \mathrm{C}\right]$ at a crosshead speed calculated to obtain a strain rate of about $5.10^{-4} \mathrm{~s}^{-1}$ in the minimum cross section. The "effective" gauge length considered, parallel to the long transverse (T) orientation, was equal to two times the radius curvature $\rho$. The specimens were instrumented with a diametral extensometer. In order to identify parameters to describe ductile damage by the local approach to fracture (see Part II), strain controlled tests with a constant radial strain rate were also carried out at ambiant temperature [12]. Control of the radial strain rate during the test allows us to obtain a whole description of the load-diameter reduction curve up to full failure, including the part of the curve after the sharp drop of the load (see fig. 3d) which cannot be obtained with constant ram displacement rate test in particular in the sharply notched geometry [37]. In the case of ductile failure, the sharp load drop corresponds to crack initiation at the center of the specimen [38]. Description of the whole curve is however important to calibrate the models developed in Part II.

The minimum diameter variation $\Delta \Phi$ was continuously recorded during the tests. Typical normalised $F / S_{0}-\Delta \Phi / \Phi_{0}$ curves are shown on fig. 3d ( $S_{0}$ : initial minimum cross section). The mean fracture strain was calculated as :

$$
\bar{\varepsilon}_{r}=2 \ln \frac{\Phi_{0}}{\Phi_{r}}
$$

where $\Phi_{0}$ and $\Phi_{r}$ are the initial and fracture minimum diameters, respectively. The mean fracture stress was obtained by :

$$
\bar{\sigma}_{r}=\frac{4 \times F_{r}}{\pi \Phi_{r}^{2}}
$$

where $F_{r}$ is the load at fracture. In the case of the initiation of a ductile macrocrack at the center of the notch, failure (i.e. $F_{r}$ and $\Phi_{r}$ ) is defined at ductile crack initiation, i.e. at the onset of the sharp load drop (fig. 3d). 


\subsection{Results}

The variations of the mean fracture strains and stresses as a function of the test temperature for the three different notch radii are reported on figures $3 a, b$ and c. The fracture mechanisms associated with each range of temperature are also indicated on these figures. As the notched specimens are used to determine the parameters needed in the models for both brittle and ductile fracture (see part II [1]), each fracture surface has been observed with SEM and classified in three main failure mode categories : brittle, ductile-brittle and fully ductile. The ductile-brittle surfaces correspond to the beginning of stable ductile tearing which was followed by unstable fracture by cleavage.

It is observed that as the notch radius increases, the temperature below which cleavage fracture is the prevaling mechanism increases and the temperature above which ductile fracture is the only mechanism decreases. When the fracture mode is fully ductile, a decrease of the test temperature increases the ductility of the material rendering the temperature stabilizing effect [39], due to a higher viscosity of the material at low temperature. Between $-150^{\circ} \mathrm{C}$ and $20^{\circ} \mathrm{C}$, the mean failure stress is continuously decreasing whereas it sligthly increases between $-196^{\circ} \mathrm{C}$ and $-150^{\circ} \mathrm{C}$. All the results obtained at temperatures below than $-150^{\circ} \mathrm{C}$ were used to calibrate the brittle fracture model [1].

Observations of the NT fracture surfaces in the ductile-brittle transition showed that ductile fracture develops firstly as several ductile islands mainly located near the center of the specimen and then link together to create larger ductile damage zones. Ductile damage was observed to develop firstly around Manganese Sulfide $(\mathrm{MnS})$ inclusions or clusters when such microstructural entities were found. The role of the MnS inclusions as weak spots of cavities nucleation and growth was already observed in similar materials [30, 37] but with higher sulfur content. The mean fracture strain is strongly dependent on the presence of such entities leading to a statistical aspect of the ductile fracture which was described in [40]. The effect of stress triaxiality ratio on the mean strain to failure (at failure initiation) is shown

on fig. 3: at room temperature the mean strain to failure is a decreasing function of the stress triaxiality ratio, as already reported for a similar steel [37, 41].

\section{Charpy tests}

\subsection{Experiments}

Standard Charpy V-notch specimens (with a $(10 \times 10) \mathrm{mm}^{2}$ section, a central $45^{\circ}$ $\mathrm{V}$-notch of $2 \mathrm{~mm}$ depth and a $0.25 \mathrm{~mm}$ notch root radius) with their notch plane perpendicular to the long transverse orientation $(\mathrm{T})$ and crack growth direction 
parallel to the longitudinal orientation of the shell (L) were tested in accordance with the French standard for impact testing of Charpy specimens (NF EN 100451) using an instrumented $300 \mathrm{~J}$ capacity impact tester, at temperatures over the range $-165^{\circ} \mathrm{C}$ to $100^{\circ} \mathrm{C}$. Interrupted Charpy impact tests (low blow tests) were also carried out at two temperatures $\left(T=-60^{\circ} \mathrm{C}\right.$ and $\left.20^{\circ} \mathrm{C}\right)$ in order to investigate ductile crack growth well before cleavage fracture as a function of impact energy. These interrupted tests were performed by imposing an initial impact energy lower than the maximum energy of 300 Joules. In addition to these impact tests at high velocity $\left(\sim 5 \mathrm{~m} \cdot \mathrm{s}^{-1}\right)$, three point-bend experiments were carried out on a 250 $\mathrm{kN}$ Instron servohydraulic machine at prescribed crosshead velocities of $1 \mu \mathrm{m} . \mathrm{s}^{-1}$ and $500 \mu \mathrm{m} . \mathrm{s}^{-1}$ over the temperature range $-196^{\circ} \mathrm{C}$ to $25^{\circ} \mathrm{C}$. A special set-up was machined to have the same contact conditions (hammer and anvils) as those for a conventional Charpy impact test. The number of specimens tested at each temperature for each velocity is given in Table 2 .

Several interrupted impact tests were also carried out to estimate the increase of temperature due to plastic deformation at high strain rate ahead of the notch. These measurements were made at room temperature and $-60^{\circ} \mathrm{C}$ by welding a tiny thermocouple $(\phi=0.1 \mathrm{~mm})$ very close $(\sim 0.1 \mathrm{~mm})$ to the notch tip on the lateral faces of Charpy specimens (see fig. 6a).

\subsection{Effect of impact velocity}

\subsubsection{Ductile-brittle transition}

Experimental CVN energies for the three velocities are reported on fig. 4. The $\mathrm{CVN}$ energies as a function of test temperature obtained at each velocity were fitted with an hyperbolic tangent function as proposed by Oldfied [42]. Parameters $A, B, C, T_{0}$ of Eq. 3

$$
C V N=A+B \tanh \left(\left(T-T_{0}\right) / C\right)
$$

are given in Table 3. $T K_{7}$ defined as the temperature for which the CVN energy is $56 \mathrm{~J}\left(70 \mathrm{~J} / \mathrm{cm}^{2}\right)$ is also reported as this temperature is currently used for the inservice evaluation of French PWR vessel steel. This temperature, as the ductile brittle transition temperature (DBTT), is often used to characterize the brittleness of a material.

The first main effect of impact velocity on CVN energy is observed on the upper shelf energy which is an increasing function of impact rate. The upper shelf decreases from about $220 \mathrm{~J}$ to $155 \mathrm{~J}$ when impact velocity decreases from $5 \mathrm{~m} . \mathrm{s}^{-1}$ to $1 \mu \mathrm{m} . \mathrm{s}^{-1}$. This behavior is mainly related to the increase of flow stress with strain rate : higher test velocity leads to a higher maximum load, the deflexion at fracture being the same when the behavior is fully ductile, the amount of energy is more 
important. This results in a higher upper shelf level.

As shown by the values of $T K_{7}$ the ductile-brittle transition temperature is not largely affected by impact velocity, contrarily to the situation usually observed in low strength ferritic steels, but similarly to what happens in a number of high strength steels [43]. If only the index $T K_{7}$ for $1 \mu \mathrm{m} . \mathrm{s}^{-1}$ and $500 \mu \mathrm{m} . \mathrm{s}^{-1}$ are considered, a positive temperature shift of $20.6^{\circ} \mathrm{C}$ is obtained, higher $T K_{7}$ value resulting from higher velocity, leading to the usually observed weakening effect of the velocity on the DBTT index. Considering now the results obtained at $500 \mu \mathrm{m} \cdot \mathrm{s}^{-1}$ and $5 \mathrm{~m} . \mathrm{s}^{-1}$, the index obtained at the higher velocity is lower $\left(\Delta T=12.7^{\circ} \mathrm{C}\right)$ as if some beneficial effect on the brittleness of the material was obtained when increasing the velocity. This is likely caused by the temperature increase reported hereafter. In any case, measured differences remain very small compared to other materials [44].

\subsubsection{Ductile tearing}

Quantitative measurements of ductile tearing were obtained from a fractographic analysis using SEM observations. From the observation of ductile area at different magnifications, the area of the ductile tearing in front of the notch was delimited and measured as a surface integral. Only the ductile area near the notch was measured (see e.g. fig. 8a) and the final ductile area (on the other side of the notch) was not considered. Dividing the area measurement by the initial thickness of the specimen ( $W=10 \mathrm{~mm}$ ), an average ductile crack length, $\Delta a_{a v}$, was determined. Moreover, due to the tunelling effect and material inhomogeneity, the distance between the notch root and the ductile crack front varies along the notch. The maximum length of this distance, $\Delta a_{\max }$, was also measured. For all specimens, $\Delta a_{a v}$ and $\Delta a_{m a x}$ were measured at the three test velocities. Results are reported on fig. 5.

Fig. 5 shows that for a given impact velocity, a clear correlation exists between the ductile crack length (both average and maximum) and the CVN energy for the tests performed at different temperatures, ductile crack length being an increasing function of the CVN energy. Influence of the testing velocity was presented elsewhere [14] and is recalled on fig. 5a and b. For both $\Delta a_{\max }$ and $\Delta a_{a v}$, for a given CVN energy, the ductile crack length is longer for quasi-static than for dynamic testing. Remembering that in the ductile-brittle transition range, similar CVN energy values are obtained under static and dynamic conditions (see section 5.2.1), it has to be kept in mind that the length of the ductile crack is different (longer) for quasi-static tests. Similar relation between the T-S (TranverseShort transverse) CVN energy and the ductile areas measured close to the notch on a similar steel has been recently found [16] and was also reported in other bainitic steels [45]. This shows that the CVN energy alone cannot account for the physical phenomena occurring during failure. More precisely, this means that the same energy can be reached for different crack advances and that the whole force- 
displacement curve must be considered.

\subsubsection{Notch root temperature rise}

Quite significant increases of the notch root temperature, $\Delta T$, were measured through interrupted low blow tests performed at $-60^{\circ} \mathrm{C}$ and $20^{\circ} \mathrm{C}$ (fig. 6b). It should be kept in mind that these temperature increases were measured on the lateral surfaces of the specimens. Results obtained with F.E. simulations showed that, as far as ductile crack growth is not too important, the temperature increases are larger in the mid-section of the specimen where plane strain conditions are prevailing [12]. This means that the $\Delta T$ increases reported in fig. $6 \mathrm{~b}$ underestimate the temperature increase in the region where brittle failure occurs more likely. Moreover these increases must be considered as values averaged over distances comparable to thermocouple dimensions $(\sim 0.1-0.2 \mathrm{~mm})$ welded at a position located at about $0.1 \mathrm{~mm}$ from the notch root. This also contributes to underestimate actual temperature increases.

The local temperature measurements raise another key point when modelling Charpy impact test is envisaged. Should the test be modelled under isothermal conditions, adiabatic conditions or under mixed conditions with heat diffusion? Simple calculations using the thermal conductivity of A508 steel ( $D \sim$ $2.10^{-5} \mathrm{~m}^{2} \mathrm{~s}^{-1}$ ) show that in a test lasting $1 \mathrm{~ms}$ the characteristic heat diffusion distance is of the order of $0.15 \mathrm{~mm}$. Typical Load versus time curves were presented elsewhere [14]. It can be shown that in the lower shelf regime the time to failure is so short that it can be assumed that fracture occurs under adiabatic conditions. On the other hand, when the value of the CVN energy is larger than about 100 Joules $\left(T \gtrsim-50^{\circ} \mathrm{C}\right.$ ) the time to failure is such that adiabatic conditions only constitute an approximation. Effects of local heating on the stress-strain state in the active process zone are presented in the companion paper (part II) [1] which illustrates the importance of taking into account the temperature increase when a local criterion is used to predict fracture in the ductile-brittle transition range (when cleavage fracture is preceded by ductile crack propagation).

\subsection{Ductile crack initiation and growth in Charpy V-notch specimens}

In this section, a particular attention is paid to the ductile crack initiation and propagation in Charpy V-notch specimens. Low blow Charpy tests performed at $-60^{\circ} \mathrm{C}$ and room temperature have been used to evaluate the ductile crack initiation and growth micromechanisms. The specimens were then broken at liquid nitrogen temperature in order to avoid any further macroscopic plastic deformation and ductile growth. Usually, the load-line displacement curve is used to separate the initiation and growth energy [46] and it is generally considered that ductile crack 
propagation roughly initiates at maximum load [47].

Observation of the ductile crack initiation for a test interrupted at a load lower than the maximum load $(\mathrm{CVN}=32 \mathrm{~J})$ is reported on fig. 7. On fig. 7a the ductile crack initiation at the notch tip is indicated by arrows. Observation in the mid-section of the specimen displayed on fig. 7a is reported on fig. 7b. It is shown that crack initiation from the notch occurs by the formation of a shear band about $100 \mu \mathrm{m}$ long, and the formation of cavities nucleated from non-metallic (e.g. MnS) inclusions located ahead of the notch tip. Macroscopically ductile crack initiation is located close to the mid-section of the specimen as shown on fig. 7a. Macroscopic ductile crack growth stages are displayed on fig. $8 \mathrm{a}$ and $\mathrm{b}$ where a fracture surface of a test interrupted just beyond the maximum load $(\mathrm{CVN}=85 \mathrm{~J})$ and formation of shear lips at the specimen lateral surfaces are shown, respectively.

Figure 8a reveals that ductile crack growth occurred with a tunneling effect, crack extension being more important in the mid-section than at the lateral surfaces. From fig. 7 and 8a, ductile crack initiation and propagation stages in the Charpy specimen are explained as follows. At first, a ductile crack is formed at the center of the notch root after yielding, for a load lower than the maximum load. As ductile crack propagates ahead of the notch, it spreads laterally and reaches the lateral surfaces by shear lips formation. At this step, the crack length in the mid-section of the specimen is about $1 \mathrm{~mm}$, and the load is just beyond the maximum load. Then the crack propagates through the thickness of the specimen with a decreasing load. Further propagation occurs with formation of shear lips at the outer surface. It is worth noting than the energy absorbed for shear lips formation is not negligible compared to the total CVN energy [46].

\section{Fractographic examinations}

Fractographic examinations were carried out to investigate the damage processes in the brittle and ductile regimes. In the first case, the nature and location of the cleavage triggering sites were studied and any modification in the DBT range was investigated. In the second case, nucleation of microvoids around second phase particles was investigated in order to determine a nucleation plastic strain threshold appropriate to the material of this study. This information will be used in the numerical models (Part II).

\subsection{Methodology}

The fracture surfaces of all the Charpy specimens that failed by cleavage during testing were examined in detail using a scanning electron microscope (SEM) 
to locate the origin of cleavage fracture and determine the nature of particles initiating fracture. In all the specimens, the cleavage mechanism is transgranular, and no intergranular decohesion has been found. Triggering sites were identified by following a network of radiating major tear and river lines. At low temperature, more than one cleavage initiation site can be found, independently of the impact velocity [48]. However, it should be mentionned that because of the difficulty of such observations, it could be sometimes difficult to differentiate the main triggering site from secondary ones. When the rivers pattern does not help to identify clearly which site is at the origin of unstable fracture, the site closer to the notch tip is taken as the principal one.

Localisation on the fracture surface of the identified triggering sites was the second step in the fractographic study. Each site was quantified by the distance, $x$, from the edge of the specimen to the cleavage triggering site, by the distance, $y_{1}$, from the notch to the triggering site and distance, $y_{2}$, from the ductile crack front to the triggering site. At low temperatures when fracture occurs before ductile crack growth, $y_{1}=y_{2}$. A similar methodology to locate the initiating sites was already applied in other studies [11]. The positions $x, y_{1}$ and $y_{2}$ are depicted on fig. 9 .

\subsection{Cleavage triggering sites}

Different natures of triggering sites have been identified : large facets with low misorientations (hereafter referenced type I), iron carbides (seldom) or second phase particle (TiC) (type II) or manganese sulfide inclusions without any ductile tearing (Type III) or associated with a ductile tearing zone (type IV) (fig. 10). Most often, due to the initiation on grain boundaries, no particular feature was found. In this last case, when cleavage rivers patterns were clearly evidenced but it was not possible to clearly identify the nature of the site, they will be referenced as "Non Identified" (NI) sites. Keep in mind that a site showing microscopic rivers converging towards a grain boundary or ductile crack tip was classified as NI sites (fig. 11). Increasing the test temperature close to the ductile-brittle transition, only one main nucleation site was found in almost all the cases.

Locations of the triggering sites on the fracture surfaces of Charpy specimens for the dynamic tests $\left(v_{0}=5 \mathrm{~m} . \mathrm{s}^{-1}\right)$ are reported on fig. 12 as a function of their nature. Sites where MnS inclusions were found (Type III and IV) are put together on fig. 12d. On this figure the closed symbols represent the distance of the cleavage triggering sites to the notch root $\left(y_{1}\right)$ and the open symbols the length of the ductile crack measured at the cleavage site position $\left(y_{1}-y_{2}\right)$. Regardless of the nature of the sites, all of them are located at least at $1.9 \mathrm{~mm}$ of the sides of the specimen, reflecting the need to reach at least a critical stress so that cleavage can be triggered. As the $\left(y_{1}-y_{2}\right)$ distance (ie the ductile crack lentgh) increases, the position of the 
site moves towards the center of the specimen, resulting from the tunnelling effect (the ductile crack is longer at the center of the specimen) occurring with ductile crack propagation (see fig. 8a). As the average ductile crack growth increases with temperature, a temperature effect for the highest temperatures on the distance $x$ could also be evidenced as recently mentionned in [15] and is shown in fig. 12. No correlation between the distance $x$ and the nature of the sites has been evidenced.

Lower temperatures (lower distance $y_{1}-y_{2}$ ) are more favorable for a triggering phenomenon which is more homogeneously distributed along the thickness of the specimen because of a more homogeneous stress state. From the observations made in this study the nature of the triggering cleavage sites does not appear to change with higher ductile crack length, i.e. higher energy (see fig. 5). In particular type IV sites could be found for both small and large ductile crack propagation (see fig. 8d). For higher energies, large facets (or several facets) with low misorientation are still found on the fracture surface (fig. 12b).

The variations of $y_{1}$ with temperature and CVN energy is reported on fig. 13a and $\mathrm{b}$, respectively. On these graphs the mean ductile crack growth, $\Delta a_{a v}$, preceding brittle cleavage fracture is also given. As observed for ductile crack growth, a large scatter is observed when examining the variation of $y_{1}$ for a given temperature. However the mean trend is an increase of $y_{1}$ with increasing temperature. Much less scatter is observed when the values of $y_{1}$ are plotted as a function of the CVN energy (fig. 13b), reflecting the increasing amount of ductile crack growth, which dissipated a large part of the energy involved in the fracture process. The results given in fig. $13 \mathrm{~b}$ also show another effect : the position of the cleavage initiating sites is located between 0.5 and $1 \mathrm{~mm}$ from the mean ductile crack front, except at large values of the $\mathrm{CVN}$ energy where the cleavage triggering sites are closer to the crack front. As previously mentionned, no correlation between the triggering cleavage site nature and temperature or CVN energy was observed.

The distance between the cleavage triggering site and the ductile crack front, $y_{2}$, is reported on fig. 14a and $\mathrm{b}$ as a function of test temperature and CVN energy, respectively. The nature of the sites is pointed out by different symbols. Here, $y_{2}$ is only given for dynamic tests $\left(v_{0}=5 \mathrm{~m} . \mathrm{s}^{-1}\right)$, results at quasi-static and intermediate velocities can be found in [12]. Here it should be only recalled that a loading rate effect could be inferred for the $y_{2}$ distance. For dynamic impact testing $\left(v_{0}=5 \mathrm{~m} . \mathrm{s}^{-1}\right)$, the triggering sites are located between 0.01 and $1.2 \mathrm{~mm}$ from the ductile crack front, with a mean distance of $0.5 \mathrm{~mm}$. For the lowest velocity, the distance $y_{2}$ varies between 0 and $0.42 \mathrm{~mm}$, the main part of the sites being located at less than $0.1 \mathrm{~mm}$ from the ductile crack front. For the dynamic tests, $y_{2}$ appears to be closer to the ductile crack front for the highest CVN energy, but this trend needs to be confirmed by further tests. From the results obtained in this study, the distance $y_{2}$ can not be correlated with the nature of the cleavage triggering sites. 


\subsection{Discussion on the nature of cleavage triggering sites}

To predict in a non-empirical way the ductile-brittle Charpy curves, approaches based on a description of local fields and on the use of appropriate models have been employed. In the DBT region these models should be able to describe the ductile crack growth preceding cleavage fracture and the cleavage mechanism provided that an accurate description of the local stress-strain fields is obtained. In many studies ductile crack growth was successfully described using fully coupled model like GTN model [49] or Rousselier model [50]. To describe cleavage at low temperature (where transgranular cleavage is the only mechanism), the Beremin model [26] was successfully applied to predict the fracture toughness variation of A508 steels. This model is based on a temperature and strain rate independent critical cleavage stress and on the weakest link theory. As other brittle fracture models [51] it is based on the postulated behavior of a population of microcracks (e.g. originating from carbides or small $\mathrm{MnS}$ particles) induced by plasticity, and one of the hypothesis is that the nature of the defects remains the same with temperature change as long as cleavage mechanism is concerned.

The role of $\mathrm{MnS}$ inclusions on the initiation of cleavage of quenched and tempered A508 steel in the DBT region was first mentionned in Rosenfield's studies [20, 52] where isolated small round inclusions $(\sim 1 \mu \mathrm{m})$ were found to be at the origin of cleavage river patterns in ferritic grains. Such small $\mathrm{MnS}$ were also observed to be at the origin of cleavage at low temperature on low sulfur $(\mathrm{S}<0.005 \% \mathrm{wt}) \mathrm{A} 508 \mathrm{cl} 3$ steel [18].

Recent studies [11, 15, 22, 23, 53] on the ductile-brittle transition of an A508 Cl.3 steel mentionned that the presence of manganese sulfide inclusions clusters has been observed in the region where cleavage was initiated leading to the formation of some ductile islands in front of the main ductile crack front. The role of $\mathrm{MnS}$ clusters was first evidenced on axisymmetric notched specimens [22] and then confirmed on Charpy and CT(1T) specimens $[11,15]$ on the same material. From these observations the role of $\mathrm{MnS}$ clusters appears to be more and more important as the testing temperature increases, representing almost $100 \%$ of the sites at $-30^{\circ} \mathrm{C}$ for Charpy specimens [15] (CVN energies between 20J and 100J).

The difficulties in the quantitative prediction of the sharp upturn in the ductiletransition region were then explained by a change in the nature of active triggering site (weak spots) with increasing temperature, the large $\mathrm{MnS}$ inclusions or clusters being the weak spots at the origin of cleavage triggering instead of carbides or small round $\mathrm{MnS}$ inclusions [15, 22, 23]. A model based on the MnS clusters was proposed in order to explain the sharp upturn of the Charpy curve in the ductile-brittle transition range [22, 23]. Following this model, the transition upturn is physically based on a change in the nature of the defects (particules/inclusions) at the origin of the cleavage as the temperature increases, leading to the conclusion 
that $\mathrm{MnS}$ inclusions clusters play an increasing role for higher energies and are at the origin of the cleavage triggering mechanism.

Contrarily to some of the above studies [15, 22, 23], the present observations on a very similar A508 Cl.3 (same heat treatment) but with a lower content of Sulphur $(0.004 \%$ instead of $0.008 \%$ for the previously mentionned studies) have not evidenced an increasing role of $\mathrm{MnS}$ inclusions with temperature (see fig. 8d), manganese sulfide inclusions clusters being even very scarcely observed on Charpy specimen fracture surfaces in this steel. However the sharp upturn in the Charpy curve is observed and is very similar to the behavior reported in these studies. A comparison of Charpy transition curves for both steels was given in [54]. Both steels present a sharp upturn in the ductile-brittle transition region. However these Charpy curves [54] were obtained with Charpy specimens tested in different orientations (T-L and T-S) so that direct quantitative comparison on the DBT temperature between these two materials cannot be made.

The discrepancy between these results could be explained by the following reasons. (i)The higher sulfur content in the previous studies (twice higher than in this study) leading to a higher propensity to form $\mathrm{MnS}$ inclusions and clusters. Based on [55], it seems that a critical density of $\mathrm{MnS}$ inclusions is necessary to enhance the role of these clusters. (ii) The effect on cleavage fracture of the orientation MnS inclusions (which can be elongated) with respect to the crack propagation direction needs to be clarified. In the present study, the length of $\mathrm{MnS}$ inclusions is perpendicular to the ductile crack front whereas it was parallel in the above mentionned studies. The role and anisotropy induced by MnS inclusions on ductile behavior of steel is well known $[37,56]$ and models leading to an accurate description of the induced mechanisms have been developed [57, 58]. However the role of large $\mathrm{MnS}$ inclusions on the initiation of cleavage fracture under large scale yielding conditions is not yet clear. Particularly, the influence of MnS inclusions or clusters located ahead of a growing ductile crack front has still to be investigated.

The DBT of the investigated steel is lower than that of the steel studied in [55]. This is possibly directly related to the lower sulfur content which reduces the number of cleavage initiation sites and avoids MnS clustering. Recent 3D numerical simulations assuming that a $\mathrm{MnS}$ cluster is an ellipsoidal void whose dimensions were experimentally determined, and applying to it boundary conditions corresponding to the stress state in front of a propagating ductile crack growth in a CT specimen, have shown that generalized plasticity occurrence leads to quite different conclusions to what can be expected from an elastic analysis [24]. Based on the mechanical properties of A508 steel described in [15, 22], numerical computations show that the unloading effect due to generalized plasticity is larger than the stress concentration effect due to the shape of the cavity. The cleavage fracture probability obtained with Beremin model is not therefore largely affected by the presence of such a defect. 
Based on the present observations, there is no drastic change in the nature of the observed cleavage triggering sites when the CVN energies increase, keeping in mind that a number of sites were not identified and that the number of these NI sites increases at higher energies. Among these NI sites, cleavage triggering on grain boundaries was observed. More observations are needed to confirm an increasing importance of plasticity induced mechanisms like dislocations pile up (e.g. Stroh or Cottrell mechanisms $[59,60]$ ). Some possible explanations to the micromechanisms at the origin of the difficulty to initiate cleavage fracture in the upper DBT range for bainitic steels can be inferred from the litterature : (i) higher propensity of the matrix to arrest microcracks cleavage propagation, (ii) a different mechanism at the origin of cleavage initiation. These two hypothesis are developed hereafter.

(i) The role of MnS clusters in A508 steel with high sulfur content could be directly linked to the first point. Cleavage facets located between a fatigue crack tip and a MnS cluster on a CT specimen were reported once [15]. MnS clusters were then presented as potential cleavage cracks arrestors. However based on this observation their role in a cleavage initiation cannot be confirmed in the DBT range. For A508 steel with low sulfur content, direct evidence of cleavage microcracks arrest was not shown in the literature as it was the case for A533 [61] and CMn [62] weld steels. Carrefull examination of the interface between ductile crack front and main cleavage area can however show features that can be interpreted as cleavage microcracks arrest event. Such event is reported on fig. 15. This figure shows a cleavage area surrounded by ductile tearing at the interface between the main ductile crack and the main cleavage area. It is clear that the cleavage microrivers in the cleavage area surrounded by ductile dimples are independent of the main cleavage crack propagation. In this area, cleavage was found to have initiated on a small round $\mathrm{MnS}$ particle. The size of this area corresponds approximately to one or two bainitic packets. One possible interpretation of this micrograph is that during the main ductile crack propagation, a cleavage microcrack has propagated and then arrested on ductile damage developed ahead of the ductile crack front (or on another microstructural barrier). Then main cleavage fracture was triggered at another location where no microstructural features was able to arrest it. Importance of cleavage arrest events related to the increase of test temperature has already been observed in HSLA bainitic steels [63]. For these steels a temperature dependence of local toughness of grain boundaries was introduced to explain a change in the size of the critical microstructural event controlling cleavage propagation . Formation of a transgranular microstructure playing the role of additionnal barriers has been evocated by Margolin et al $[64,65]$ to introduce a plastic strain dependence of the critical stress controlling the propagation of cleavage fracture on an $2 \mathrm{Cr}-\mathrm{Ni}-\mathrm{Mo}-\mathrm{V}$ pressure vessel steel. Further investigations have to be carried out to confirm this mechanism in bainitic A508 Cl.3 steels.

(ii) A change in the micromechanisms controlling cleavage fracture in the DBT range to explain the observed sharp upturn was also recently discussed in the 
literature [24]. Based on thin foils observations (TEM), a change of the triggering cleavage plasticity mechanisms, as mechanical twins or shear bands presence was observed [66] and could be the physical micromechanism at the origin of the sharp upturn in the DBT range for tempered bainitic A508 steel. Further investigations using TEM and EBSD techniques should provide a better understanding and clarify the different hypothesis.

\subsection{Nucleation around second phase population}

Nucleation around second phase population is well known to play an important role in the ductile damage mechanisms, as much at the beginning of the deformation history, as during the coalescence phase (localized necking) [31]. The role of $\mathrm{Fe}_{3} \mathrm{C}$ carbides in the nucleation of microcavities and in the localisation of the deformation is illustrated on fig. 16 for the steel of this study. Fig. 16a corresponds to a SEM zoom of the ductile crack shown in fig $7 \mathrm{~b}$. On this figure the crack tip is located on the top right corner. Following the slip lines path a ductile crack propagates between a sharp crack and a ductile cavity nucleated from a MnS located ahead of the crack tip. In this zone where plastic strain levels are very high, nucleation of microcavities develops from $\mathrm{Fe}_{3} \mathrm{C}$ carbides as observed in fig. 16c. Fig. 16b shows a path between the sharp crack tip and the void (indicated by white arrows). Along this path, nucleation of microcavities has originated around $\mathrm{Fe}_{3} \mathrm{C}$ carbides due to the localisation of the deformation. It shows the crucial role of such particules in the larger voids linking process by softening the material and in the coalescence mechanism.

Based on the numerical work by Chu and Needleman [67], most of the studies describing the nucleation around a second phase population have used a Gaussian distribution of the nucleation strain around a mean equivalent plastic strain, $\bar{\varepsilon}_{N}$, adding three new parameters for the modelling of the ductile damage. Most often two of the nucleation parameters are directly taken from numerical pionnering studies $[49,68]$, and the third one is adjusted either on experimental macroscopic curves or indirectly [69]. However it was shown that the role of the second phase population on the failure mechanism strongly depends on the value of $\bar{\varepsilon}_{N}$ [70], and that it is desirable to obtain them directly from the metallurgical analysis of the material.

In the present study, the experimental procedure presented in [71] was followed : Charpy specimens loaded to a predetermined amount of energy (low blow tests) and axisymmetric notched bars loaded either to fracture or to prescribed reductions of area corresponding to severe deformation were observed with SEM, after etching with Villela solution, in longitudinal sections located on the central axis (fig. 17a). As previously stated, these observations have shown that secondary voids are 
nucleated on cementite $\left(\mathrm{Fe}_{3} \mathrm{C}\right)$ carbides (fig. 17b). Estimation of the plastic strain threshold was obtained by finite element analysis [12]. The plastic strain at the location where voids around $\mathrm{Fe}_{3} \mathrm{C}$ were firtsly observed was taken as the plastic threshold for the nucleation around second phase population. A plastic threshold of about 0.5 was found and then considered for the simulations presented in the companion paper [1].

\section{Summary and conclusions}

One heat of a low sulfur (0.004 wt \%) pressure vessel A508 steel, representative of modern steels used for the fabrication of nuclear pressure vessels, with a quenched and tempered microstructure has been thoroughly investigated. The main aims of this investigation were to identify the micromechanisms responsible for the ductile to brittle transition and to determine the input data necessary for modeling this transition. Mechanical tests and microfractographic observations have been performed on smooth tensile specimens, notched bars and on Charpy V-notch specimens.

The mechanical response of smooth bars was found to be strongly temperature and strain-rate dependent when tested over range of temperature $\left[-196^{\circ} \mathrm{C}, 100^{\circ} \mathrm{C}\right]$ and strain-rates $\left[4.10^{-4} \mathrm{~s}^{-1}, 4.10^{3} \mathrm{~s}^{-1}\right]$. These tests on smooth bars are useful for the identification of the constitutive laws used in the numerical simulations of Charpy V-notch specimens.

Quasi-static tests on notched specimens with different notch radii and thus different stress triaxiality ratios showed that the ductile to brittle transition behavior was dependent on specimen geometry. All the quantities (stress-strain curves, strains and stresses to failure) necessary to identify the models used for ductile rupture and cleavage fracture were measured over the temperature range corresponding to a single mechanism of failure. In particular, the scatter in cleavage test results obtained on these notched specimens can be used to develop a statistical model for cleavage fracture.

Charpy $\mathrm{V}$-notch tests were carried out over a wide temperature range between $-196^{\circ} \mathrm{C}$ and $100^{\circ} \mathrm{C}$, using three widely different loading rates (1 $\mu \mathrm{m} . \mathrm{s}^{-1}, 500 \mu \mathrm{m} . \mathrm{s}^{-1}$ and $\left.5 \mathrm{~m} . \mathrm{s}^{-1}\right)$. In this steel, no apparent drastic effect of the loading rate on the ductile to brittle transition temperature was noted. However it was observed that the upper shelf energy increases significantly with loading rate. Local measurement of temperature using tiny thermocouples welded very close $(0.1 \mathrm{~mm})$ to the notch tip revealed a significant heating effect during impact testing at $5 \mathrm{~m} . \mathrm{s}^{-1}$ corresponding to quasi-adiabatic conditions. Temperature increases of the order of $150^{\circ} \mathrm{C}$ were detected when an impact energy of 85 Joules corresponding to the ductile to brittle transition was applied. These temperature increases are likely largely underestimated. Measurements of ductile crack growth preceding cleavage fracture in the transition regime were made. The tunneling 
effect due to preferential ductile crack growth in the center of Charpy specimens was evidenced and quantitatively studied. This indicates that a $3 \mathrm{D}$ modeling must necessarily be adopted for simulating Charpy V-notch test.

Detailed microfractographic observations showed that cleavage cracks were initiated from differents types of nucleation sites including (i) large facets with low misorientations, (ii) iron carbides, second phase particles (TiC) or manganese sulfide $(\mathrm{MnS})$ inclusions. The nature of these sites and their positions with respect to the notch tip and the location of advancing ductile crack front were systematically determined. No systematic variations in the nature of cleavage initiating sites with test temperature were evidenced. In particular, no preferential initiation from $\mathrm{MnS}$ inclusions at increasing temperature was observed, contrarily to other observations reported in the literature. This situation is likely due to the low sulfur content present in this material. Cleavage initiating sites were shown to be preferentially located in the mid-section of the Charpy specimens, which again underlines the importance of 3D simulations. The position of the cleavage triggering sites was observed to be closer to the ductile crack growth front when the impact energy corresponds to the upper part of the DBT range. This suggests that the position of the maximum principal stress ahead of an 3D propagating crack should shift nearer to the crack front for increasing crack advances.

Further metallographic and fractographic observations showed that ductile rupture involved a double population of cavities. In addition to those easily initiated from large $\mathrm{MnS}$ inclusions, smaller cavities initiated from $\mathrm{Fe}_{3} \mathrm{C}$ particles were observed. A quantitative analysis performed on notched bar specimens showed that these smaller cavities corresponding to the second population were initiated after relatively large strains $(>0.5$ ) contrarily to the situation associated to $\mathrm{MnS}$ particles which easily separate from the matrix. These observations are useful to simulate ductile damage using the mechanics of porous ductile materials with a nucleation law for ductile damage based on experimental observations.

\section{Acknowledgments}

Financial support from Direction de la Sureté des Installations Nucléaires (DSIN) and Electricité de France $(\mathrm{EdF})$ is acknowledged. Technical support from B. Marini (CEA-Saclay), Y.Grandjean (EdF-Chinon), J. Clisson (CTA-Arcueil) and G. Brabant (EMP) is also greatly acknowledged. 


\section{References}

[1] B. Tanguy, J. Besson, R. Piques, A. Pineau, Ductile to brittle transition of a A508 steel characterized by the Charpy impact test. Part-II: modeling of the Charpy transition curve, Engng Fract Mech (2004), in press.

[2] R. O. Ritchie, W. Server, R. Wullaert, Critical fracture stress and fracture strain models for the prediction of lower and upper shelf toughness in nuclear pressure vessel steels, Met. Trans. A 10A (1979) 1557-1570.

[3] L. Xia, L. Cheng, Transition from ductile tearing to cleavage fracture: a cellmodel approach, Int J Frac 87 (1997) 289-306.

[4] M. Goldthorpe, C. Wiesner, Micromechanical prediction of fracture thoughness for pressure vessel steel using a coupled model, in: T. Panotin, S. Sheppard (Eds.), Fatigue and Fracture Mechanics : Twenty-Ninth volume, ASTM STP 1332, 1999, pp. 341-363.

[5] C. Eripret, D. Lidbury, A. Sherry, I. Howard, Prediction of fracture in the transition regime : application to an A533B pressure vessel steel, in: Les Editions de Physique (Ed.), 1st european mechanics of materials conference on local approach to fracture, Journal de Physique IV, Vol. 6, Fontainebleau, 9-11 Septembre, 1996, pp. C6-315-C6-323.

[6] G. Bernauer, W. Brocks, W. Schmitt, Modifications of the Beremin model for cleavage fracture in the transition region of a ferritic steel, Engng Fract Mech 64 (1999) 305-325.

[7] Böhme, W. and Bernauer, G. and Schmitt, W., Scatter of a ferritic steel in the transition region analyzed by Charpy tests and dynamic tensile tests, Nuc. Engng and Design 188 (1999) 149-154.

[8] Schmitt, W. and Sun, D.Z. and Bernauer, G. and Nagel, G. , New approaches to improve the RPV materials database, Nuc. Engng and Design 183 (1998) $1-8$.

[9] J. Heerens, D. Hellmann, Development of the Euro fracture toughness datatest, Engng Fract Mech 69 (2002) 421-449.

[10] I. Howard, Z. Li, M. Sheikh, Local approach predictions of transition behaviour of specimens and structures, in: 20 years of R6, proceedings of one-day seminar organised by the Materials and Mechanics of Solids Group, IMechE HQ, London, 1996, p. 9.

[11] M. Mantyla, A. Rossoll, I. Nedbal, C. Prioul, B. Marini, Fractographic observations of cleavage fracture initiation in a bainitic A508 steel, J. Nuclear Materials 264 (1999) 257-262.

[12] B. Tanguy, Modélisation de l'essai Charpy par l'approche locale de la rupture. Application au cas de l'acier 16MND5 dans le domaine de la transition, Ph.D. thesis, Ecole des Mines de Paris, http://pastel.paristech.org/ documents/disk0/00/00/02/28/index.html (2001).

[13] B. Tanguy, J. Besson, R. Piques, A. Pineau, Numerical Modeling of Charpy V-notch tests, in: D. François, A. Pineau (Eds.), From Charpy to present impact testing, ESIS Publication 30, 2002, pp. 461-468.

[14] B. Tanguy, R. Piques, A. Pineau, Experimental analysis of Charpy V-notch 
specimens, in: D. François, A. Pineau (Eds.), From Charpy to present impact testing, ESIS Publication 30, 2002, pp. 453-460.

[15] A. Rossoll, C. Berdin, C. Prioul, Determination of the fracture toughness of a low alloy steel by the instrumented Charpy impact test, Int J Frac 115 (2002) 205-226.

[16] P. Hausild, I. Nebdal, C. Berdin, C. Prioul, The influence of ductile tearing on fracture energy in the ductile-to-brittle transition temperature range, Mater Sci Engng A 335 (2002) 164-174.

[17] G. Gibson, M. Capel, S. Druce, Effect of heat treatment on the fracture toughness transition properties of an A508 Class 3 steel, in: J. Blauel, K.H. Schwalbe (Eds.), Defect assessment in components-Fundamentals and applications, ESIS/EGF9, Mechanical Engineering publications, 1991, pp. 587-611.

[18] S. Druce, G. Gibson, M. Capel, Microstructural control of cleavage fracture in an A508 steel class 3 pressure vessel steel, in: H. Ernst, A. Saxena, D. McDowell (Eds.), Fracture Mechanics : Twenty second symposium (Volume I), ASTM STP 1131, 1992, pp. 682-706.

[19] X. Zhang, J. , Knott, The statistical modelling of brittle fracture in homogeneous and heterogeneous steel microstructures, Acta mater. 48 (2000) 2135-2146.

[20] A. Rosenfield, D. Shetty, A. Skidmore, Fractographic observations of cleavage initiation in the ductile-brittle transition region of a reactorpressure-vessel steel, Met. Trans. A 14 (1983) 1934-1937.

[21] A. Rosenfield, D. Shetty, Cleavage fracture of steel in the upper ductile-brittle transition region, Engng Fract Mech 17 (5) (1983) 461-470.

[22] S. Renevey, S. Carassou, B. Marini, C. Eripret, A. Pineau, Ductile-brittle transition of ferritic steels modelled by the local approach to fracture, in: Les Editions de Physique (Ed.), 1st european mechanics of materials conference on local approach to fracture, Journal de Physique IV, Vol. 6, Fontainebleau, 9-11 Septembre, 1996, pp. C6-343-C6-352.

[23] S. Carassou, S. Renevey, B. Marini, A. Pineau, Modelling of the ductile to brittle transition of a low alloy steel, in: ECF 12, Fracture from defects, Vol. II, 1998, pp. 691-696.

[24] P. Hausild, P. Bompard, C. Berdin, C. Prioul, M. Karlik, Influence of ductile tearing on cleavage triggering in ductile-to-brittle transition of A508 steel, in: D. François, A. Pineau (Eds.), From Charpy to present impact testing, ESIS Publication 30, 2002, pp. 79-86.

[25] B. Gurovich, E. Kuleshova, O. Lavrenchuk, Comparative study of fracture in pressure vessel steels A533B and A508, J. Nuclear Materials 228 (1996) 330-337.

[26] F. Beremin, A local criterion for cleavage fracture of a nuclear pressure vessel steel, Met. Trans. 14A (1983) 2277-2287.

[27] D. Moinereau, J. Frund, J. Brochard, B. Marini, P. Joly, D. Guichard, S. Bhandari, A. Sherry, D. Sanderson, C. France, D. Lidbury, Local approach to fracture applied to reactor pressure vessel : synthesis of a cooperative 
programme between EDF, CEA, Framatome and AEA, in: Les Editions de Physique (Ed.), 1st european mechanics of materials conference on local approach to fracture, Journal de Physique IV, Vol. 6, Fontainebleau, 9-11 Septembre, 1996, pp. C6-243-C6-255.

[28] W. Schmitt, D. Sun, J. Blauel, Damage mechanics analysis (Gurson model) and experimental verification of the behaviour of a crack in a weld-cladded component, Nuc. Eng. Design 174 (1997) 237-246.

[29] E. Busso, Y. Lei, N. O’Dowd, G. Webster, Mechanistic prediction of fracture processes in ferritic steel welds within the transition temperature regime, $\mathrm{J}$ Engng Mater Technology 120 (1998) 328-337.

[30] F. Beremin, Cavity formation from inclusions in ductile fracture of A508 steel, Met. Trans. 12A (1981) 723-731.

[31] M. Isacsson, T. Narström, Microscopic examination of crack growth in a pressure vessel steel, Mat. Sci. and Eng. A 241 (1998) 169-178.

[32] T. Narström, M. Isacsson, Microscopic investigation of cleavage initiation in modified A508B pressure vessel steel, Mat. Sci. and Eng. A 271 (1999) 224231.

[33] A. G. Franklin, Comparison between a quantitative microscope and chemical methods for assessment of non-metallic inclusions, J. of The Iron and Steel Institute 207 (1969) 181-186.

[34] B. Tanguy, R. Piques, L. Laiarinandrasana, A. Pineau, Mechanical behaviour of A508 steel based on double nonlinear viscoplastic constitutive equation, in: D. Miannay, P. Costa, D. François, A. Pineau (Eds.), EUROMAT 2000, Advances in Mechanical Behaviour. Plasticity and Damage, Elsevier, 2000, pp. $499-504$.

[35] J. Campbell, W. Ferguson, The temperature and strain-rate dependence of the shear strength of mild steel, Phil. Mag. 21 (1970) 63-82.

[36] F. Beremin, Calculs élastoplastiques par la méthode des éléments finis d'éprouvettes axisymétriques entaillées circulairement, Journal de mécanique appliquée 4 (3) (1980) 307-325.

[37] J. Lautridou, A. Pineau, Crack initiation and stable crack growth resistance in A508 steels in relation to inclusion distribution, Engng Fract Mech 15 (1-2) (1981) 55-71.

[38] A. Mackenzie, J. Hancock, D. Brown, On the influence of state of stress on ductile failure initiation in high strength steels, Engng Fract Mech 9 (1977) 167-188.

[39] B. Tanguy, J. Besson, An extension of the Rousselier model to viscoplastic temperature dependant materials, Int J Frac 116 (2002) 81-101.

[40] K. Decamp, L. Bauvineau, J. Besson, A. Pineau, Size and geometry effects on ductile rupture of notched bars in a C-Mn steel: Experiments and modelling, Int J Frac 88 (1) (1998) 1-18.

[41] F. Beremin, Effect of stress-triaxiality on the ductile tearing and the cleavage fracture of a mild steel, Journal de mécanique appliquée 4 (3) (1980) 327-342.

[42] W. Oldfield, Curve fitting impact test data : a statistical procedure, ASTM Standardizations news (1975) 24-29. 
[43] S. Rolfe, J. Barsom, Fracture and fatigue control in structures. Applications of fracture mechanics., Prentice-Hall,Inc., 1977.

[44] Lam Thanh, L., Acceptibilité de défauts en rupture fragile dans les soudures d'aciers pour tubes : modèles FAD et approche locale, Ph.D. thesis, Ecole des Mines de Paris (2003).

[45] B. Tanguy, D. Siegele, Investigation of the Mastercurve concept relating to applicability for German nuclear power plants fr a 22NiMoCr 3-7 material, Tech. rep., Fraunhofer IWM institute, Freiburg (2002).

[46] T. Kobayashi, K. Takai, H. Maniwa, Transition behaviour and evaluation of fracture toughness in Charpy impact test, Transactions ISIJ 7 (1967) 115-125.

[47] H. Ma, L. Zhu, Z. Wang, Unified correlations in transition temperatures of low alloy steels and weld metals of various toughnesses, Fatigue Fract Engng Mater Struct 19 (1996) 1459-1480.

[48] D. Rittel, B. Tanguy, A. Pineau, T. Thomas, Impact fracture of a ferritic steel in the lower shelf regime, Int J Frac 117 (2002) 101-112.

[49] V. Tvergaard, A. Needleman, Analysis of cup-cone fracture in a round tensile bar, Acta metall. 32 (1984) 157-169.

[50] G. Rousselier, Ductile fracture models and their potential in local approach of fracture, Nuc. Eng. Design 105 (1987) 97-111.

[51] Wallin, K. and Saario, T. and Törrönen, K., Statistical model for carbide induced brittle fracture in steel, Metal Science 18 (1984) 13-16.

[52] A. Rosenfield, D. Shetty, Cleavage fracture of steel in the ductile-brittle transition region, in: E. Wessel, F. Loss (Eds.), Elastic-Plastic Fracture Test Methods : The User's Experience, ASTM STP 856, 1985, pp. 196-209.

[53] A. Rossoll, C. Berdin, P. Forget, C. Prioul, B. Marini, A local approach to cleavage fracture of A508 steel, in: ECF 12, Fracture from defects, Vol. II, 1998, pp. 637-642.

[54] A. Rossoll, M. Tahar, al., Local approach of the Charpy test at low temperature, in: Les Editions de Physique (Ed.), 1st european mechanics of materials conference on local approach to fracture, Journal de Physique IV, Vol. 6, Fontainebleau, 9-11 Septembre, 1996, pp. C6-279-C6-286.

[55] S. Carassou, Déclenchement du clivage dans un acier faiblement allié : rôle de l'endommagement ductile localisé autour des inclusions, Ph.D. thesis, Ecole des Mines de Paris (2000).

[56] S. Norris, J. Parker, The effect of microstructure on fracture mechansims of 2.25Cr1Mo low alloy steel, part A : the influence of non-metallic inclusions, Int. J. Pres. Ves. and Piping 67 (1996) 317-327.

[57] A. Benzerga, J. Besson, A. Pineau, Coalescence-controlled anisotropic ductile fracture, J. Eng. Mat. Eng. 121 (1999) 121-229.

[58] T. Pardoen, J. Hutchinson, An extended model for void growth and coalescence, J. Mech. Phys. Solids 48 (12) (2000) 2467-2512.

[59] A. Cottrell, Theory of brittle fracture in steels and similar metals, Transactions of the Metallurgical Society of AIME 212 (1958) 192-203.

[60] A. Stroh, A theory of the fracture of metals, Advances in Physics 6 (1957) 517. 
[61] X. Zhang, R. Armstrong, G. Irwin, Cleavage fracturing stages at micrometresize inclusions in pressure vessel steel weld metal, J. of Mat. Sci. letters 5 (1986) 961-964.

[62] J. Tweed, J. Knott, Effect of reheating on microstructural and toughness of C-Mn weld metal, Metal Science 17 (1983) 45-54.

[63] A. Lambert, X. Garat, T. Sturel, A. Gourgues, A. Gingell, Application of acoustic emission to the study of cleavage fracture mechanism in a HSLA steel, Scripta mater. 43 (2000) 161-166.

[64] B. Margolin, V. Shvetsova, G. Karzov, Brittle fracture of nuclear pressure vessel steels-i. local criterion for cleavage fracture, Int. J. Pres. Ves. and Piping 72 (1997) 73-87.

[65] B. Margolin, G. Karzov, V. Shvetsova, Brittle fracture of nuclear pressure vessel steels-ii. prediction of fracture toughness, Int. J. Pres. Ves. and Piping 72 (1997) 89-96.

[66] M. Karlik, I. Nebdal, J. Siegl, Microstructure of a reactor pressure vessel steel close to the zones of ductile tearing and cleavage, Mater Sci and Engng A 357 (2003) 423-428.

[67] C. Chu, A. Needleman, Void nucleation effects in biaxially stretched sheets, J Engng Mater Technology 102 (1980) 249-256.

[68] K. Mathur, A. Needleman, V. Tvergaard, Ductile failure analyses on massively parallel computers, Comput. Methods Appl. Mech. Engrg. 119 (1994) 283-309.

[69] R. Narasimhan, A. Rosakis, B. Moran, A three-dimensional numerical investigation of fracture initiation by ductile failure mechanism ia a 4340 steel, Int J Frac 56 (1992) 1-24.

[70] W. Brocks, D. Sun, A. Hönig, Verification of the transferability of micromechanical parameters by cell model calculations with visco-plastic materials, Int. Journal of Plasticity 11 (8) (1995) 971-989.

[71] J. Fisher, J. Gurland, Void nucleation in spheroidized carbon steels. Part 1 : Experimental, Metal Science 15 (1981) 185-192. 


\section{List of Figures}

1 Microstructure of A508 (16MND5) steel. a: Optical micrograph (Nital 2\% etched), b and c: SEM micrograph (electrolytically etched) (b : secondary electron and $\mathrm{c}$ : back scattered electron). A bainitic paquet is indicated by an arrow.

2 Yield stress versus temperature at different strain rates for A508 steel. Comparaison between model and experiments.

3 Evolution of the mean fracture strains and stresses with temperature for notched specimens NT ( $a, b$ and $c)$. Fracture mechanisms are indicated on each figure; $\mathrm{C}$ : cleavage with few ductile cavities, DBT : ductile-brittle transition, DC : presence of delaminated cleavage, $\mathrm{D}$ : ductile tearing. $\mathrm{d}$ : Examples of Load-diameter reduction curves obtained with $\mathrm{NT}_{4}$ specimen geometry. Fracture mechanisms are indicated on each curve. The cross symbol corresponds to the unstable fracture of the specimen. The round symbol corresponds to an interrupted test.

4 Charpy V-notch (CVN) fracture toughness transition curves of 16MND5 (A508) for T-L Charpy specimens tested at different loading rates.

5 Loading rate effect on ductile crack length a) maximum ductile crack lentgh b) average ductile crack length. Round, square and losange symbols are for dynamic, intermediate and quasi-static loading velocity, respectively. For each symbol shape, a given pattern represents a given temperature.

6 Temperature increase during Charpy test a) Location of the tiny thermocouple at the notch tip b) Temperature rise versus impact energy measured at notch tip during interrupted Charpy-V tests.

7 Ductile crack initiation at the notch of a Charpy V-notch specimen. $T=-60^{\circ} \mathrm{C}, \mathrm{CVN}=32 \mathrm{~J}$. a) Ductile tearing at the notch tip is indicated by white arrows b) Mid-section of a Charpy specimen. Cavities are indicated by a black arrow.

8 Ductile crack growth from the notch of a Charpy V-notch specimen. $T=-60^{\circ} \mathrm{C}, \mathrm{CVN}=85 \mathrm{~J}$. a) Fracture surface with a tunelling effect of ductile crack growth b) Lateral specimen surface where fracture gives rise to the formation of shear lips (indicated by white arrows) 
9 Quantities measured in Charpy specimens during fractographic study

10 Different types of cleavage triggering sites. a) several facets with low misorientations, b) cementite carbide associated with a ductile cavity c) second phase particle (TiC), d) Manganese Sulfide inclusion.

11 Example of a triggering cleavage site located at the vicinity of a large elongated ductile cavity. a) Convergence of the cleavage microscopic rivers ahead of a ductile cavity b) Location of the triggering site close to the cavity. c) Higher magnification reveals a zone with slip lines prints (A) without any microscopic cleavage rivers, potential cleavage initiation location is indicated by a white arrow. $T=-60^{\circ} \mathrm{C}, \mathrm{CVN}=50 \mathrm{~J}$.

12 Location of the triggering cleavage sites on the fracture surface of Charpy specimen as a function of their identified nature. Closed symbols $\left(y_{1}\right)$, open symbols $\left(y_{1}-y_{2}\right)$.

13 Distance between notch tip and cleavage triggering sites with the nature of cleavage sites. a) with temperature b) with CVN energy.

14 Distance between ductile crack front (or notch tip when $\Delta a=0$ ) and cleavage triggering sites with the nature of cleavage sites. a) with temperature b) with CVN energy.

15 Microcracks cleavage area surrounded by ductile tearing at the interface between main ductile crack growth and cleavage fracture. The ductile crack propagates from top to bottom. The cleavage micro-rivers observed in the cleavage area surrounded by ductile tearing (top center of the figure) are independent on the main cleavage propagation. $T=-80^{\circ} \mathrm{C}$.

16 Mechanism of microscopic ductile crack growth at the macroscopic ductile crack initiation at a Charpy V-notch tip. a) Zoom of the ductile crack at notch tip on fig. 7b. b) microvoids nucleation at $\mathrm{Fe}_{3} \mathrm{C}$ carbides along strain localization path c) microvoids nucleation close to the ductile crack tip.

17 Scanning electron micrographs of longitudinal section showing a) specimen orientation b) voids around $\mathrm{Fe}_{3} \mathrm{C}$ particles. 


\begin{tabular}{c|c|c|c|c|c|c|c|c|c|c|}
\hline $\mathrm{C}$ & $\mathrm{S}$ & $\mathrm{P}$ & $\mathrm{Si}$ & $\mathrm{Mn}$ & $\mathrm{Ni}$ & $\mathrm{Cr}$ & $\mathrm{Mo}$ & $\mathrm{Cu}$ & $\mathrm{Co}$ & $\mathrm{V}$ \\
\hline 0.16 & 0.004 & 0.008 & 0.22 & 1.33 & 0.76 & 0.22 & 0.51 & 0.07 & 0.017 & $\leq 0.01$ \\
\hline
\end{tabular}

Table 1

Chemical composition of A508 Cl.3 steel (wt.\%). 


\begin{tabular}{|c|c|c|c|}
\hline$T\left({ }^{\circ} \mathrm{C}\right)$ & $v_{0}=5 \mathrm{~m} \cdot \mathrm{s}^{-1}$ & $v_{0}=500 \mu \mathrm{m} \cdot \mathrm{s}^{-1}$ & $v_{0}=1 \mu \mathrm{m} \cdot \mathrm{s}^{-1}$ \\
\hline-196 & & 1 & 1 \\
\hline-165 & 1 & 1 & \\
\hline-140 & & 1 & 1 \\
\hline-120 & 2 & 1 & 2 \\
\hline-100 & 4 & 1 & 3 \\
\hline-90 & 4 & & \\
\hline-80 & 7 & 5 & 6 \\
\hline-60 & 11 & 3 & 6 \\
\hline-45 & 7 & 3 & 4 \\
\hline-30 & 4 & & \\
\hline-20 & 3 & 3 & 2 \\
\hline 0 & 3 & & 1 \\
\hline RT & 2 & 2 & 1 \\
\hline 100 & 2 & & \\
\hline Total & 50 & 21 & 27 \\
\hline
\end{tabular}

Table 2

Number of specimens tested for each temperature and velocity. 


\begin{tabular}{c|c|c|c|c|c}
\hline$v_{0}$ & $A$ & $B$ & $T_{0}\left({ }^{\circ} \mathrm{C}\right)$ & $\mathrm{C}$ & $T K_{7}\left({ }^{\circ} \mathrm{C}\right)$ \\
\hline $5 \mathrm{~m} . \mathrm{s}^{-1}$ & 108.5 & 105 & -50.8 & 48.4 & -78.4 \\
$500 \mu \mathrm{m} . \mathrm{s}^{-1}$ & 85.6 & 83.4 & -49 & 45 & -65.7 \\
$1 \mu \mathrm{m} . \mathrm{s}^{-1}$ & 82.2 & 78 & -66.6 & 56.3 & -86.3 \\
\hline
\end{tabular}

Table 3

Parameters of the CVN energy fitting function and index $T K_{7}$ for different test velocities. 




Fig. 1. Microstructure of A508 (16MND5) steel. a: Optical micrograph (Nital 2\% etched), $\mathrm{b}$ and $\mathrm{c}$ : SEM micrograph (electrolytically etched) (b : secondary electron and $\mathrm{c}$ : back scattered electron). A bainitic paquet is indicated by an arrow. 


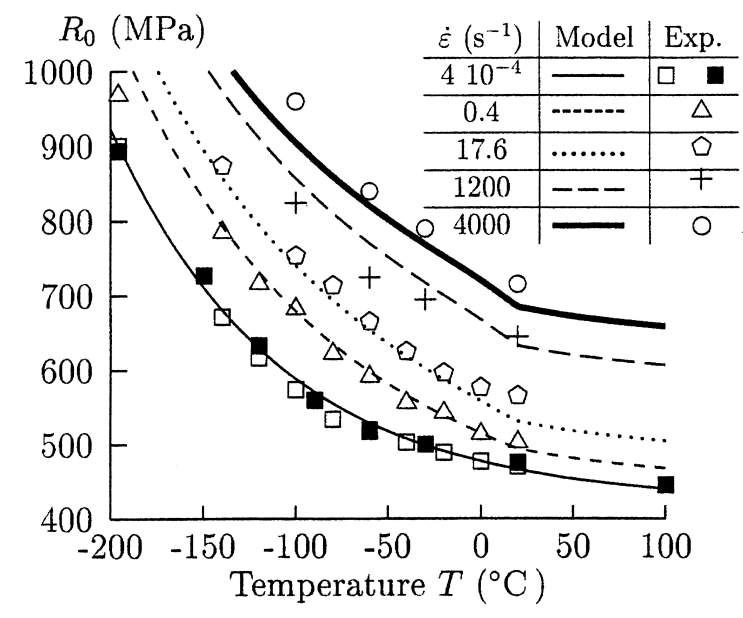

Fig. 2. Yield stress versus temperature at different strain rates for A508 steel. Comparaison between model and experiments. 

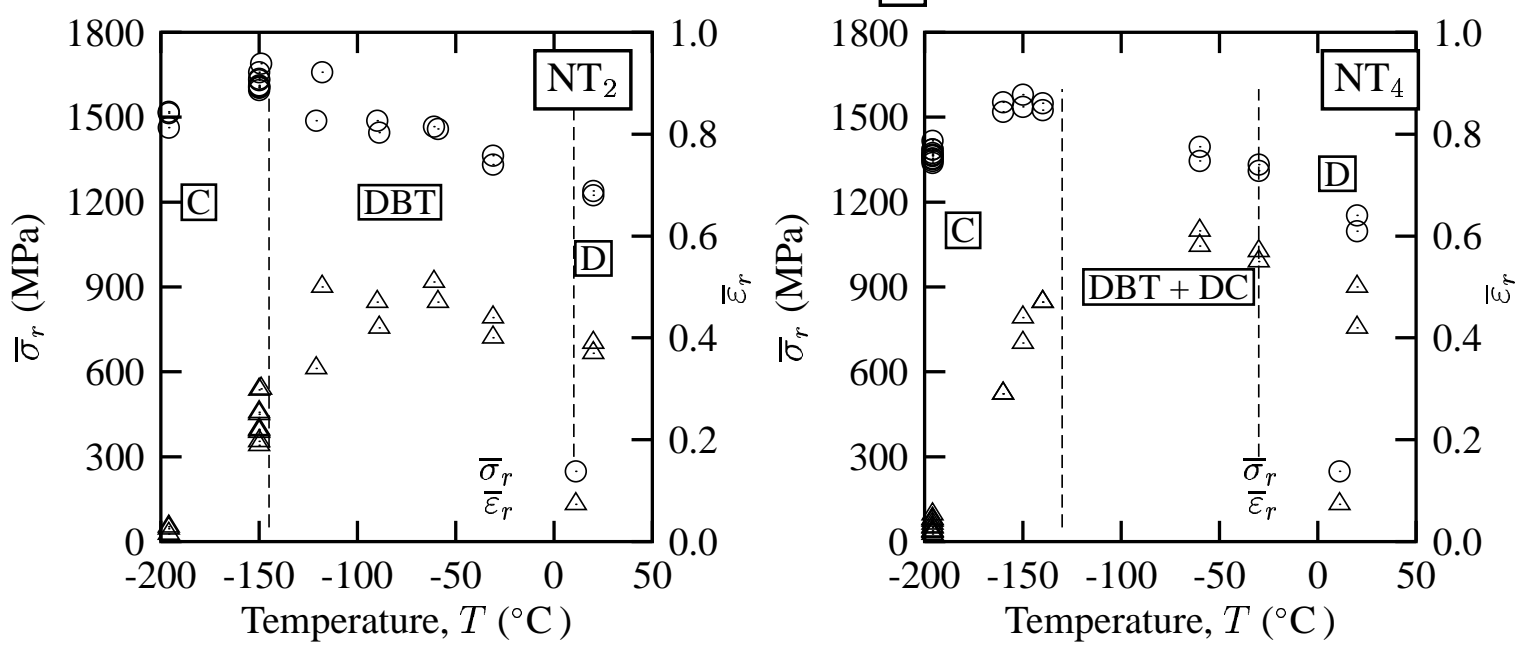

$\mathrm{c}$

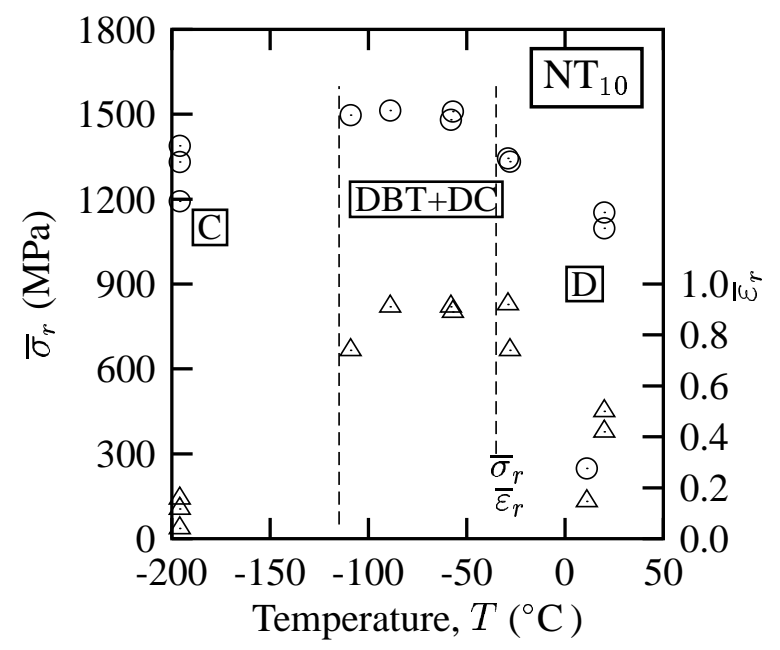

$\mathrm{d}$

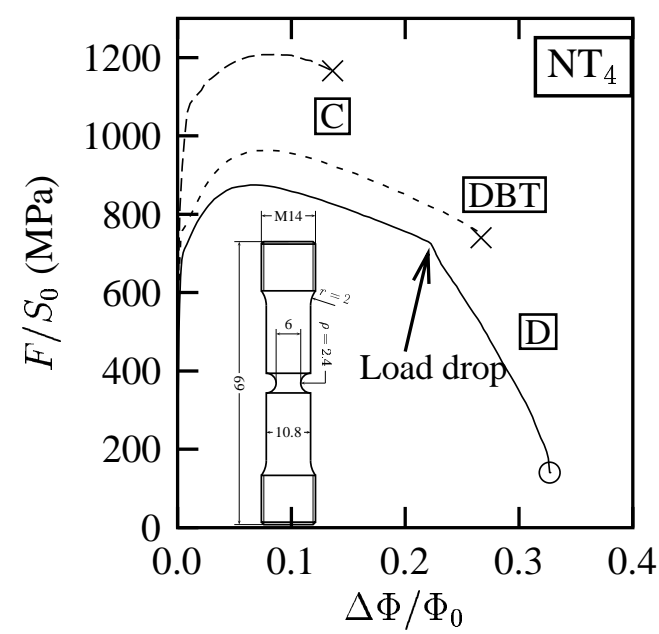

Fig. 3. Evolution of the mean fracture strains and stresses with temperature for notched specimens NT ( $a, b$ and $c)$. Fracture mechanisms are indicated on each figure; $\mathrm{C}$ : cleavage with few ductile cavities, DBT : ductile-brittle transition, DC : presence of delaminated cleavage, D : ductile tearing. $\mathrm{d}$ : Examples of Load-diameter reduction curves obtained with $\mathrm{NT}_{4}$ specimen geometry. Fracture mechanisms are indicated on each curve. The cross symbol corresponds to the unstable fracture of the specimen. The round symbol corresponds to an interrupted test. 


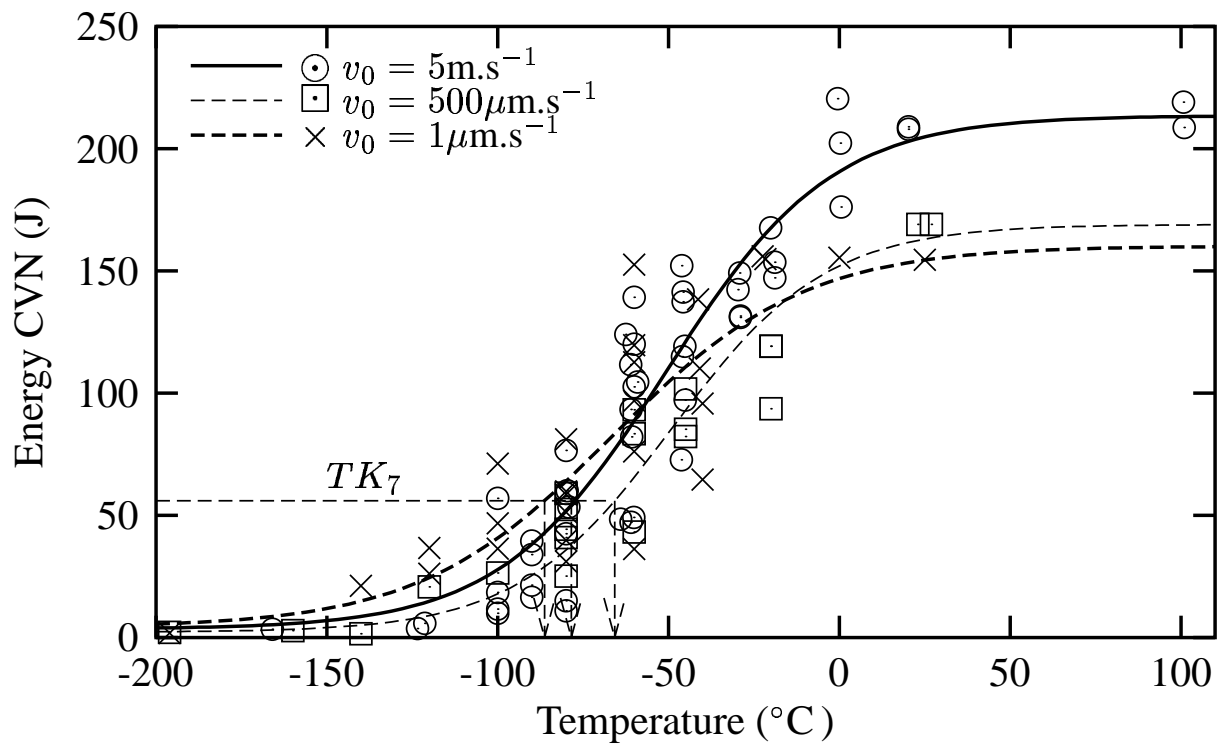

Fig. 4. Charpy V-notch (CVN) fracture toughness transition curves of 16MND5 (A508) for T-L Charpy specimens tested at different loading rates. 

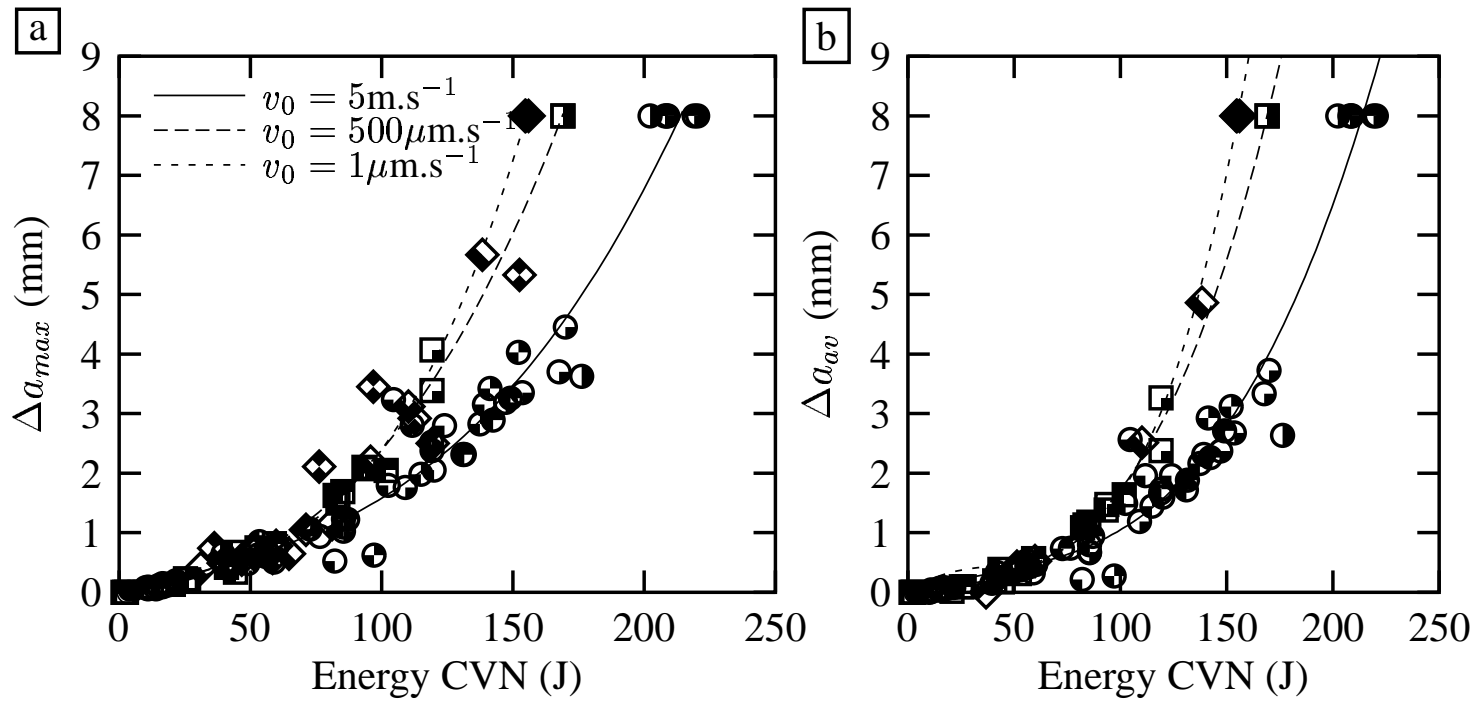

Fig. 5. Loading rate effect on ductile crack length a) maximum ductile crack lentgh b) average ductile crack length. Round, square and losange symbols are for dynamic, intermediate and quasi-static loading velocity, respectively. For each symbol shape, a given pattern represents a given temperature. 



Fig. 6. Temperature increase during Charpy test a) Location of the tiny thermocouple at the notch tip b) Temperature rise versus impact energy measured at notch tip during interrupted Charpy-V tests. 



Fig. 7. Ductile crack initiation at the notch of a Charpy V-notch specimen. $T=-60^{\circ} \mathrm{C}, \mathrm{CVN}=32 \mathrm{~J}$. a) Ductile tearing at the notch tip is indicated by white arrows b) Mid-section of a Charpy specimen. Cavities are indicated by a black arrow. 



Fig. 8. Ductile crack growth from the notch of a Charpy V-notch specimen. $T=-60^{\circ} \mathrm{C}, \mathrm{CVN}=85 \mathrm{~J}$. a) Fracture surface with a tunelling effect of ductile crack growth b) Lateral specimen surface where fracture gives rise to the formation of shear lips (indicated by white arrows) 


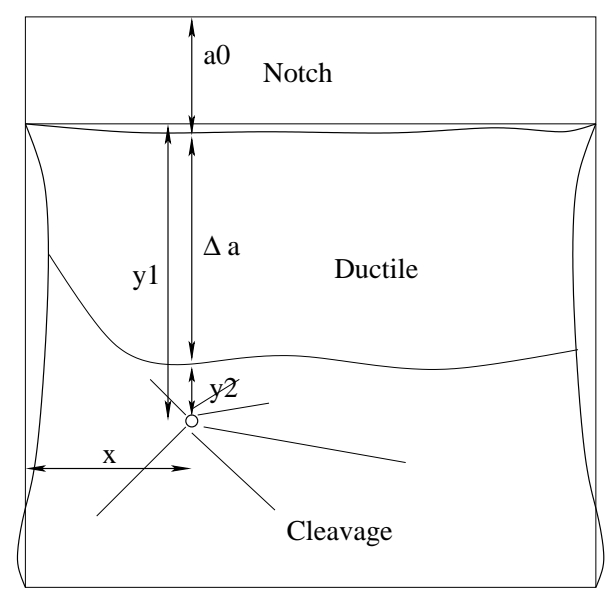

Fig. 9. Quantities measured in Charpy specimens during fractographic study 

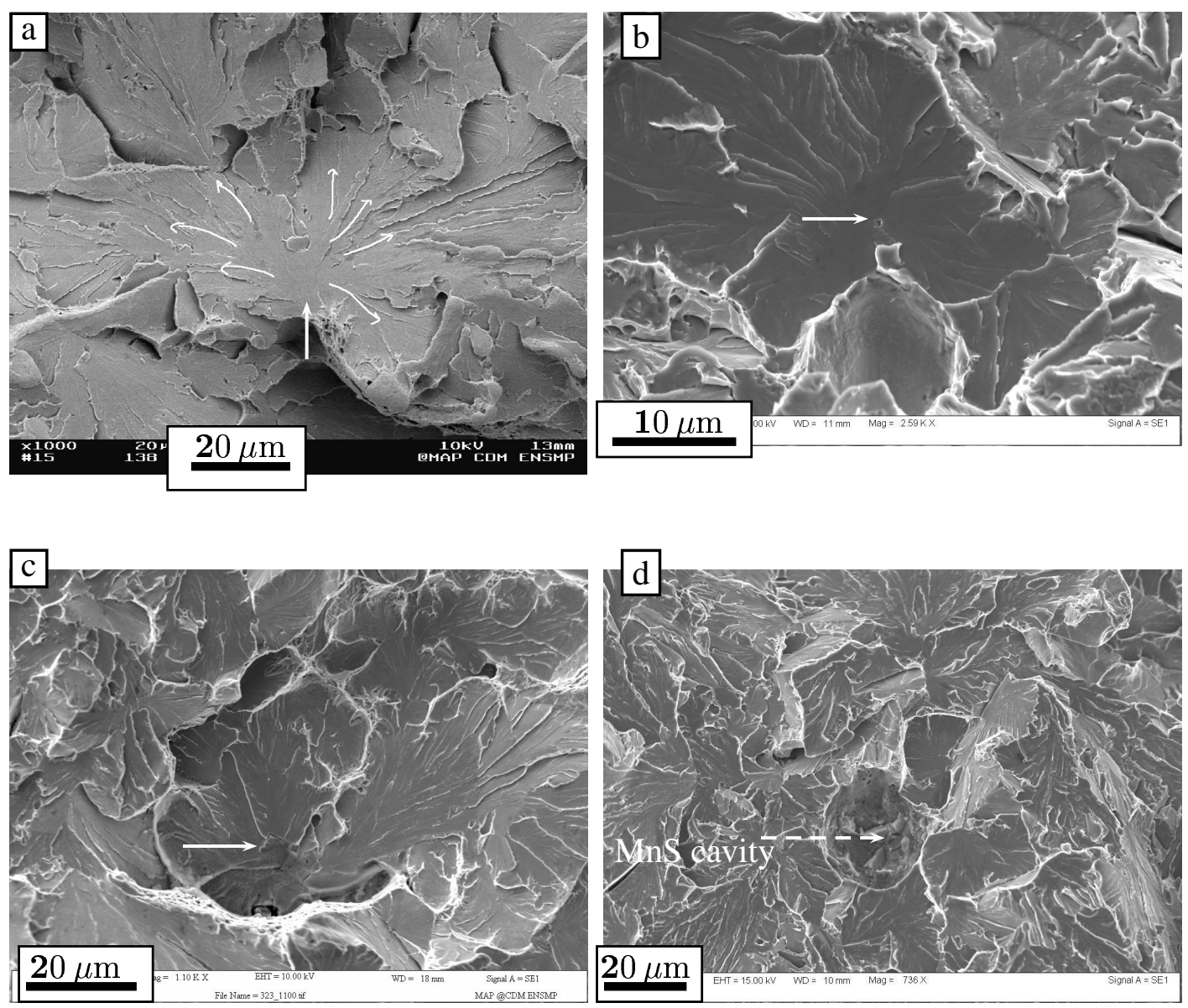

Fig. 10. Different types of cleavage triggering sites. a) several facets with low misorientations, b) cementite carbide associated with a ductile cavity c) second phase particle (TiC), d) Manganese Sulfide inclusion. 

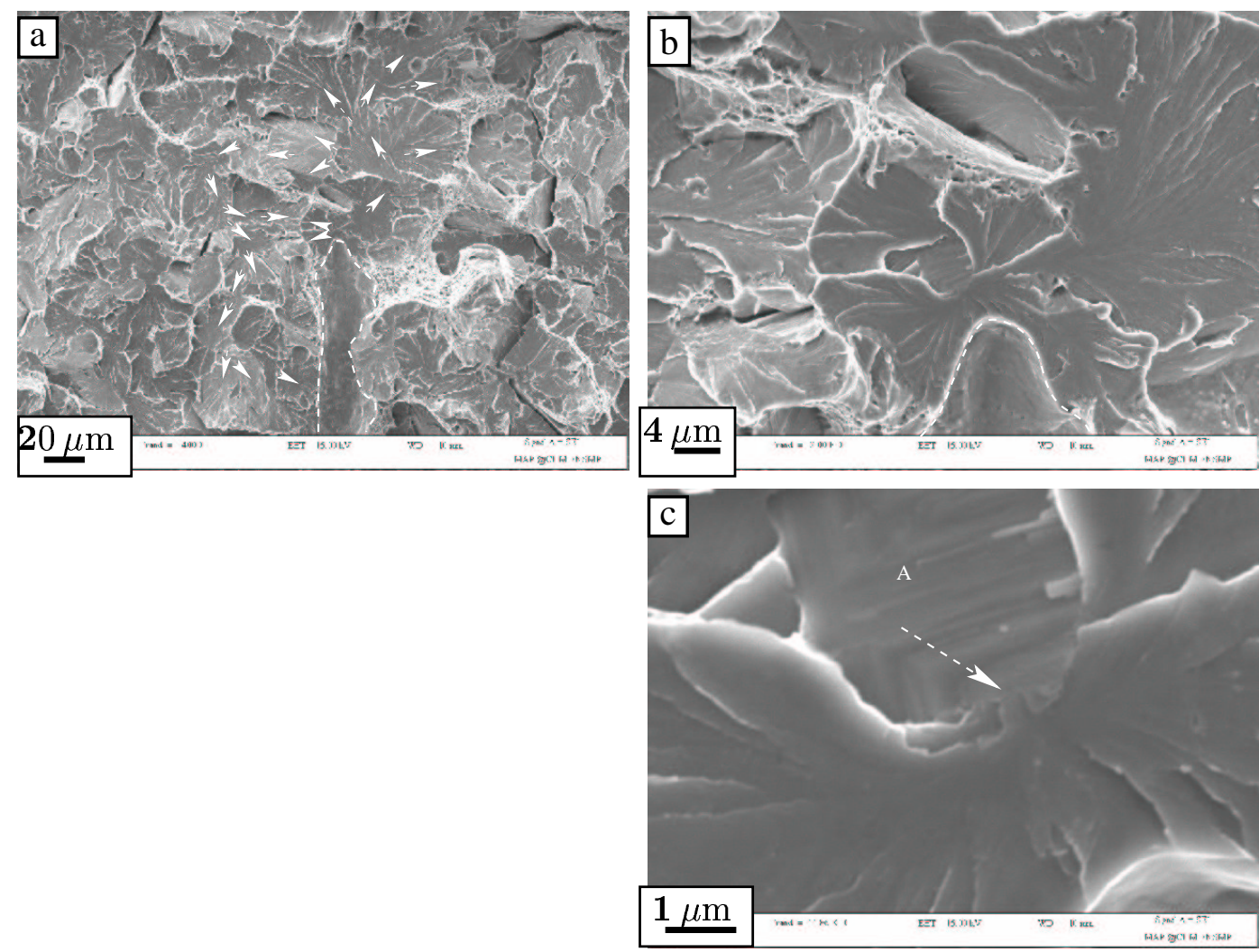

Fig. 11. Example of a triggering cleavage site located at the vicinity of a large elongated ductile cavity. a) Convergence of the cleavage microscopic rivers ahead of a ductile cavity b) Location of the triggering site close to the cavity. c) Higher magnification reveals a zone with slip lines prints (A) without any microscopic cleavage rivers, potential cleavage initiation location is indicated by a white arrow. $T=-60^{\circ} \mathrm{C}, \mathrm{CVN}=50 \mathrm{~J}$. 

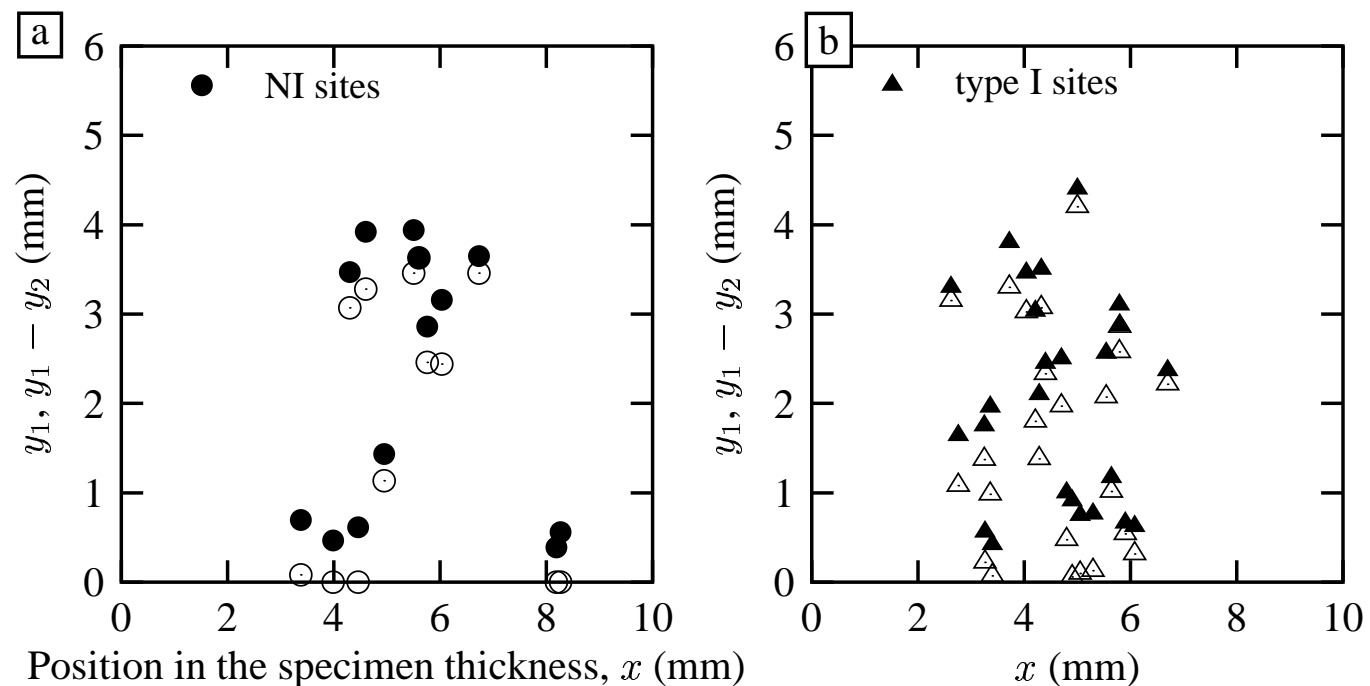

Position in the specimen thickness, $x(\mathrm{~mm})$
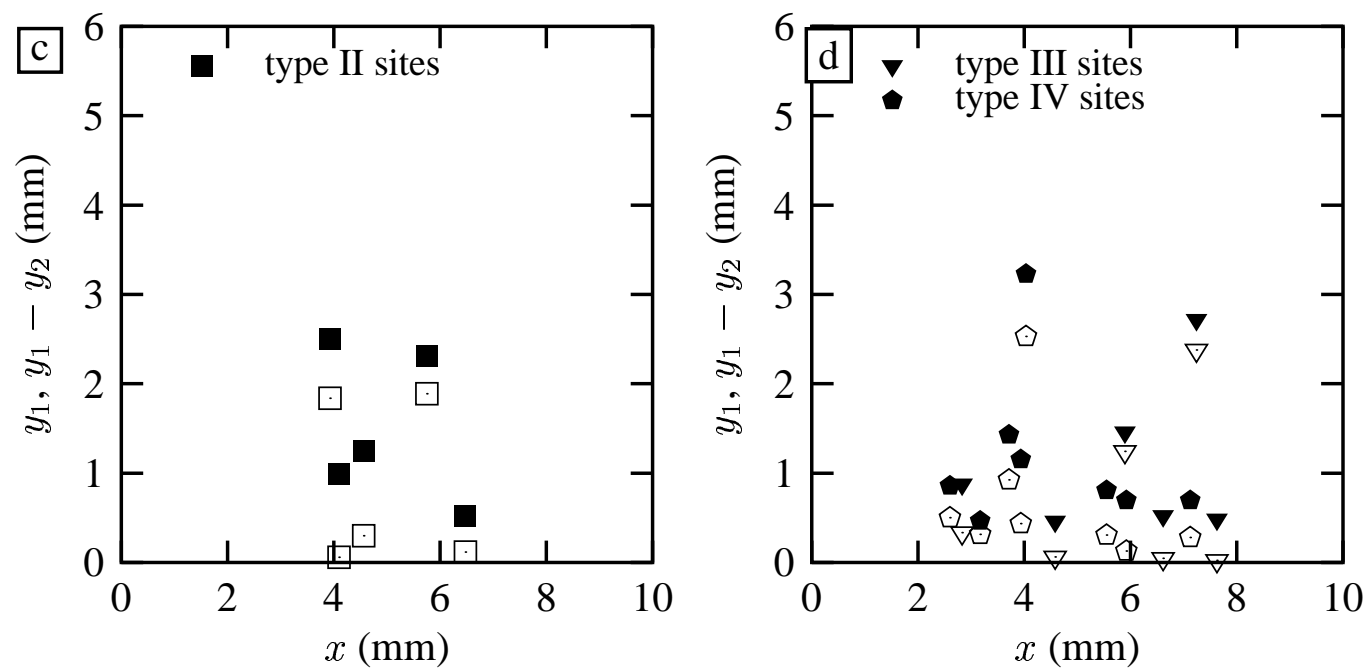

Fig. 12. Location of the triggering cleavage sites on the fracture surface of Charpy specimen as a function of their identified nature. Closed symbols $\left(y_{1}\right)$, open symbols $\left(y_{1}-y_{2}\right)$. 

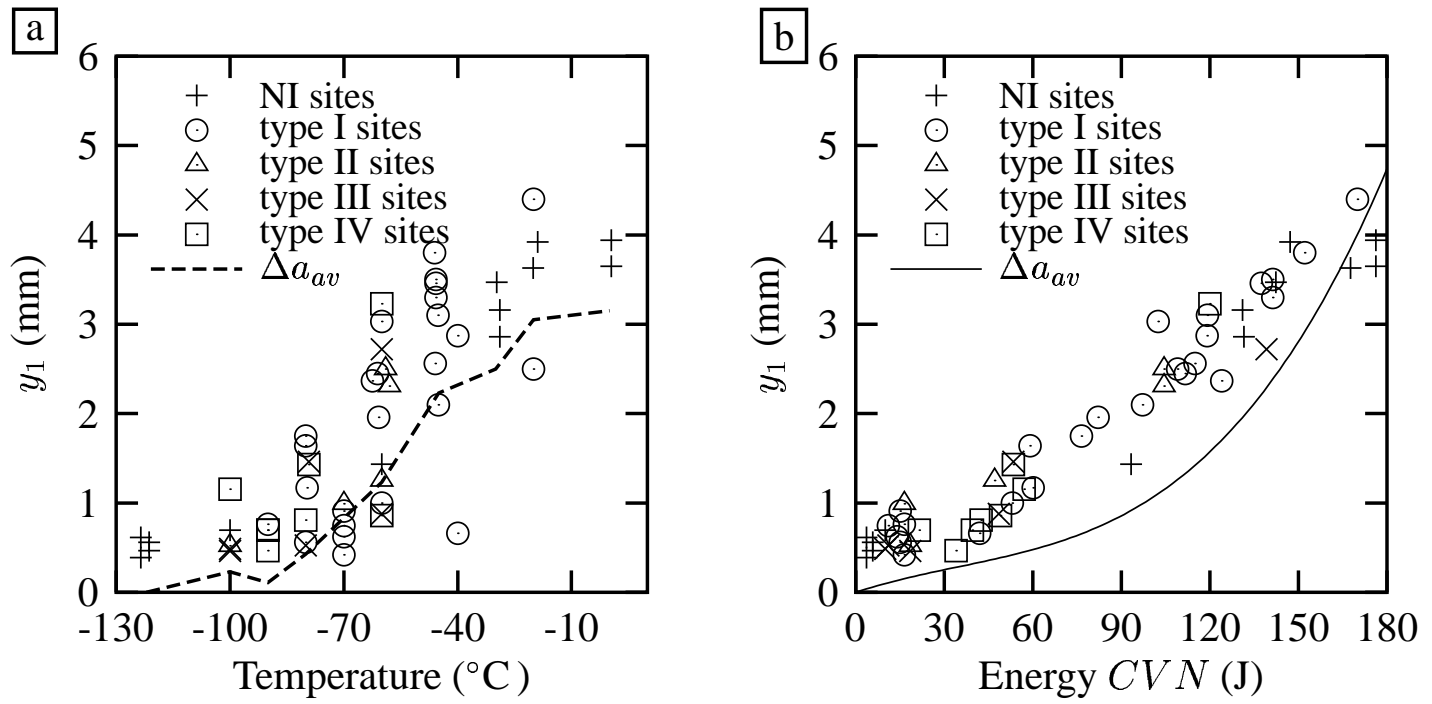

Fig. 13. Distance between notch tip and cleavage triggering sites with the nature of cleavage sites. a) with temperature b) with CVN energy. 
NI sites + , type I sites $\odot$, type II sites $\triangle$, type III sites $\nabla$, type IV sites


Fig. 14. Distance between ductile crack front (or notch tip when $\Delta a=0$ ) and cleavage triggering sites with the nature of cleavage sites. a) with temperature b) with CVN energy. 


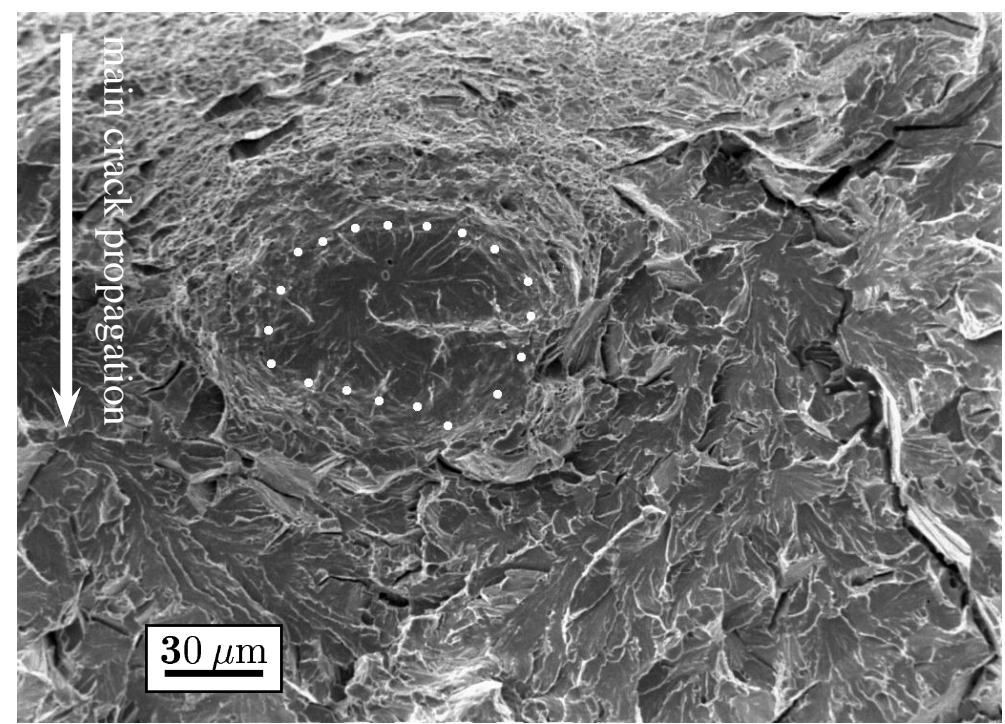

Fig. 15. Microcracks cleavage area surrounded by ductile tearing at the interface between main ductile crack growth and cleavage fracture. The ductile crack propagates from top to bottom. The cleavage micro-rivers observed in the cleavage area surrounded by ductile tearing (top center of the figure) are independent on the main cleavage propagation. $T=-80^{\circ} \mathrm{C}$. 


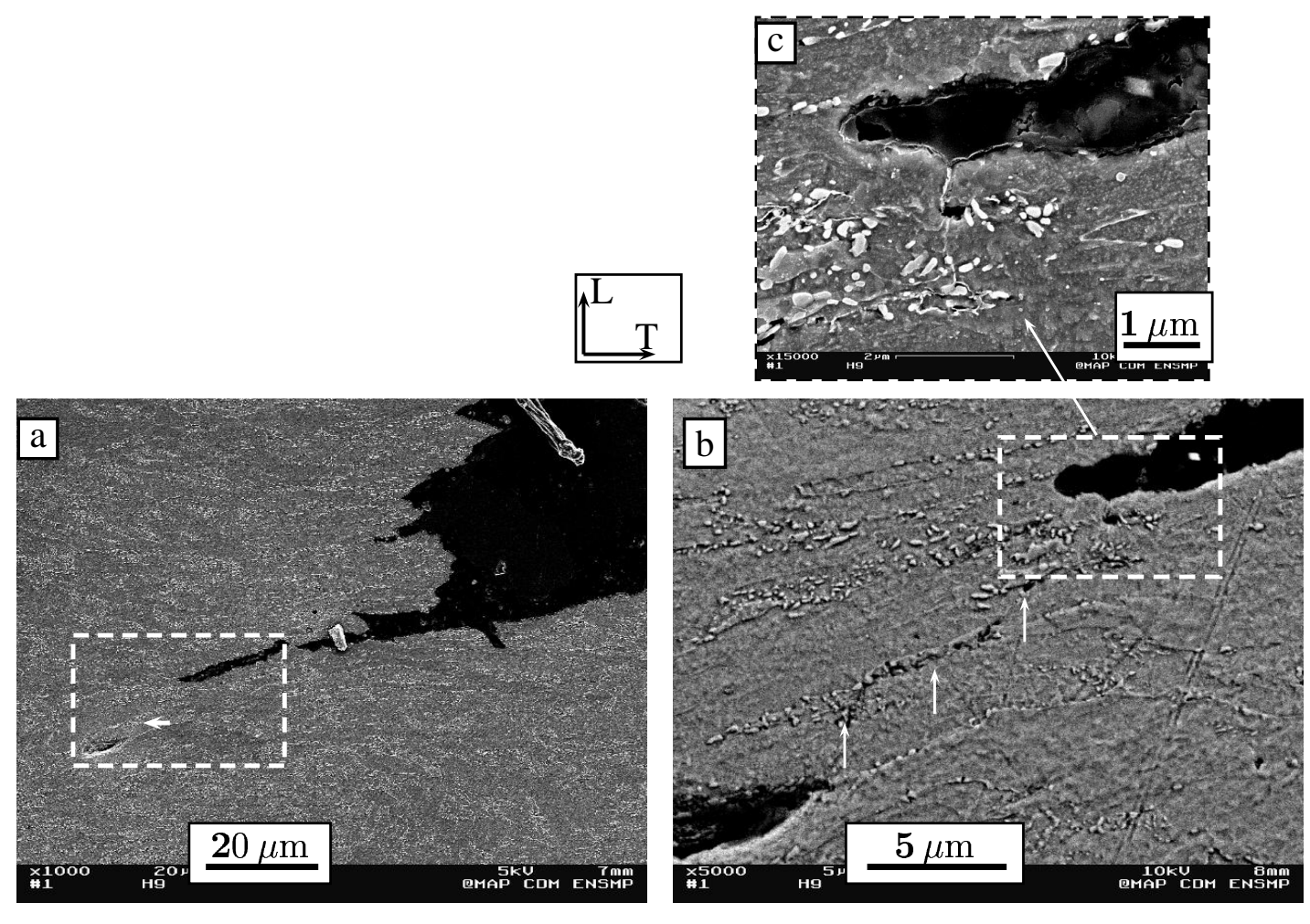

Fig. 16. Mechanism of microscopic ductile crack growth at the macroscopic ductile crack initiation at a Charpy V-notch tip. a) Zoom of the ductile crack at notch tip on fig. 7b. b) microvoids nucleation at $\mathrm{Fe}_{3} \mathrm{C}$ carbides along strain localization path c) microvoids nucleation close to the ductile crack tip. 




Fig. 17. Scanning electron micrographs of longitudinal section showing a) specimen orientation b) voids around $\mathrm{Fe}_{3} \mathrm{C}$ particles. 